\title{
Simulations of Sizing and Comfort Improvements for Residential Forced-Air Heating and Cooling Systems
}

May 2002

Walker, I., Degenetais, G. and Siegel, J.

Energy Performance of Buildings Group Lawrence Berkeley National Laboratory Berkeley, CA 


\section{$\underline{\text { Table of contents }}$}

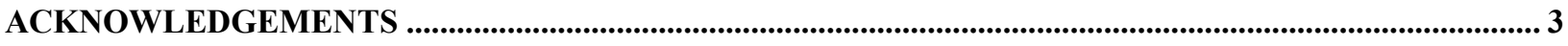

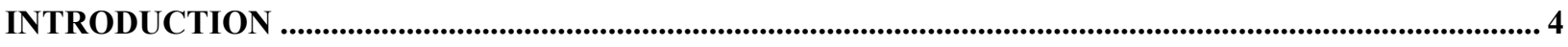

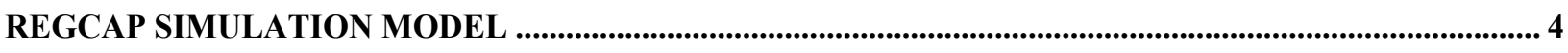

COMPARISON BETWEEN MEASURED DATA AND REGCAP SIMULATIONS ................................... 7

WEATHER DATA AND HOUSE/SYSTEM FEATURES ......................................................................................... 11

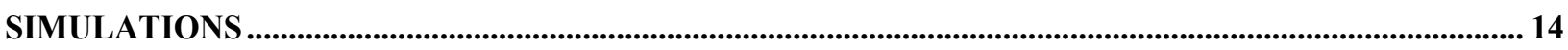

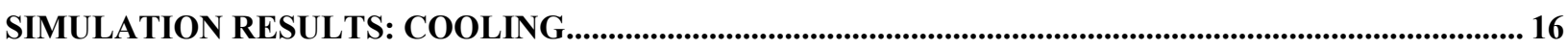

SIMULATION RESULTS: HEATING ......................................................................................................................... 26

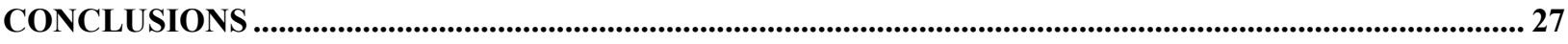

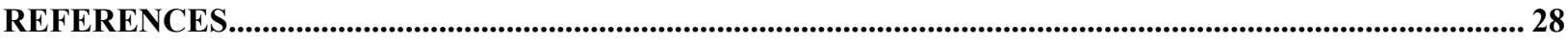

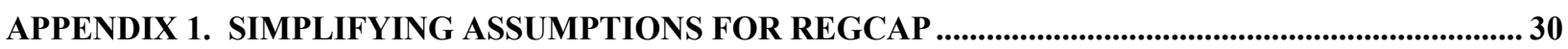

APPENDIX 2: CALIFORNIA CLIMATE ZONES .................................................................................................. 33

APPENDIX 3: MEAN ALTITUDE AND LATITUDE OF EACH CLIMATE ZONE ....................................... 34

APPENDIX 5: PEAK AND DESIGN WEATHER DATA FOR EACH CLIMATE ZONE............................... 35

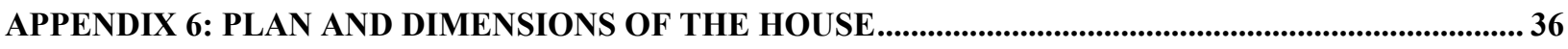

APPENDIX 7: DETAILS OF HOUSE DESCRIPTION USED AS INPUT TO REGCAP................................. 39

APPENDIX 8: ACCA MANUAL J FURNACE SIZING SUMMARY .................................................................. 41 


\section{ACKNOWLEDGEMENTS}

This study was sponsored by the California Institute for Energy Efficiency (CIEE) through the U.S. Department of Energy. The research reported here was funded by the California Institute for Energy Efficiency (CIEE), a research unit of the University of California. Publication of research results does not imply CIEE endorsement of or agreement with these findings, nor that of any CIEE sponsor.

The Energy Performance of Buildings Group of Lawrence Berkeley National Laboratory developed this project for the Pacific Gas and Electric Company under Contract S9902A, to support PG\&E's energy efficiency programs in new and existing residential buildings. The Project Manager for PG\&E is Lance Elberling (with the assistance of Marshall Hunt).

The authors would like to thank Jennifer McWilliams and Darryl Dickerhoff of the Energy Performance of Buildings Group for their technical assistance and support. 


\section{INTRODUCTION}

In many parts of North America residential HVAC systems are installed outside conditioned space. This leads to significant energy losses and poor occupant comfort due to conduction and air leakage losses from the air distribution ducts. In addition, cooling equipment performance is sensitive to air flow and refrigerant charge that have been found to be far from manufacturers specifications in most systems. The simulation techniques discussed in this report were developed in an effort to provide guidance on the savings potentials and comfort gains that can be achieved by improving ducts (sealing air leaks) and equipment (correct air-flow and refrigerant charge). The simulations include the complex air flow and thermal interactions between duct systems, their surroundings and the conditioned space. They also include cooling equipment response to air flow and refrigerant charge effects. Another key aspect of the simulations is that they are dynamic to account for cyclic losses from the HVAC system and the effect of cycle length on energy and comfort performance.

To field test the effect of changes to residential HVAC systems requires extensive measurements to be made for several months for each condition tested. This level of testing is often impractical due to cost and time limitations. Therefore the Energy Performance of Buildings Group at LBNL developed a computer simulation tool that models residential HVAC system performance. This simulation tool has been used to answer questions about equipment downsizing, duct improvements, control strategies and climate variation so that recommendations can be made for changes in residential construction and HVAC installation techniques that would save energy, reduce peak demand and result in more comfortable homes. Although this study focuses on California climates, the simulation tool could easily be applied to other climates.

This report summarizes the simulation tool and discusses the significant developments that allow the use of this tool to perform detailed residential HVAC system simulations. The simulations have been verified by comparison to measured results in several houses over a wide range of weather conditions and HVAC system performance. After the verification was completed, more than 350 cooling and 450 heating simulations were performed. These simulations covered a range of HVAC system performance parameters and California climate conditions (that range from hot dry deserts to cold mountain regions). The results of the simulations were used to show the large increases in HVAC system performance that can be attained by improving the HVAC duct distribution systems and by better sizing of residential HVAC equipment. The simulations demonstrated that improved systems can deliver improved heating or cooling to the conditioned space, maintain equal or better comfort while reducing peak demand and the installed equipment capacity (and therefore capital costs).

This study concentrated on an extreme location for HVAC systems: in the attic (where it is hot during the cooling operation and cold during heating operation). This is the most difficult location to model because the attic has extreme diurnal temperature changes due to solar radiation and is sensitive to other weather conditions because of high ventilation rates. Other more thermally stable duct locations (such as crawlspaces and garages) will be studied in future work.

This study was based on a simulation program (REGCAP) that was used to systematically analyze heating and cooling performance for residential buildings. This program has been used and validated in previous studies (Walker et al. 2001, Siegel et al. 2000 and Walker et al. 1998). The simulated house is based on the "standard" house defined by the California Energy Commission (CEC 1998 and 1999) for the California State Energy Code (known as Title 24) compliance. Sixteen different climate zones of California (also defined by CEC) were used as the climate data for the simulations.

\section{REGCAP SIMULATION MODEL}

The REGCAP (short for REGister CAPacity) model was developed because existing models of residential HVAC system performance either have too many simplifying assumptions (e.g., proposed ASHRAE Standard 152P, ASHRAE (2001)), or do not adequately model the ventilation, thermal and moisture performance of the ducts and the spaces containing ducts. The attic thermal and air flow elements were developed from existing models outlined and validated previously by Wilson and Walker (1991 and 1992). Additional validation of the attic ventilation and thermal model has been discussed in Forest and Walker (1993a) and (1993b). A key attribute for the REGCAP simulation tool that makes it unique is that the ventilation air flow rates are calculated from building envelope leakage parameters, weather data and calculations of wind shelter effects, rather than requiring these air flow rates to 
be known by the user of the simulation. Previous studies discussed in the above references showed how the capability of calculating attic air flow rates is essential in determining the attic air temperatures, which in turn is very important when determining the HVAC system losses.

The model does not explicitly include any moisture transport phenomena. This is mainly due to the lack of verified models of moisture performance for buildings in general and specifically, those that can be used based on the simple information available for a house. For example, we could not find a simple verified model for air conditioner moisture performance (particularly one that would include the transient effects required in our modeling). Although the attic model has the capability to determine the moisture content of the attic air based on outdoor, indoor and attic wood conditions (Forest and Walker (1993a) and (1993b)), there is no equivalent model for indoor air moisture, mostly due to large unknowns in the hydroscopic performance of the house furnishings and the large impact occupants have on indoor moisture. Lastly, the houses tested for verification purposes were in dry climates.

The air flow modeling in REGCAP combines ventilation models for the house and attic with duct, register, and leakage flows using a mass balance of air flowing in and out of the house, attic and duct system. The thermal modeling uses a lumped heat capacity approach so that transient effects are included. The ventilation and thermal models interact because the house and attic ventilation rates are dependent on house and attic air temperatures, and the energy transferred by the duct system depends on the attic and house temperatures.

For air flows, the house and attic are both treated as single zones. Most attic spaces are of open construction and a single zone is a good assumption. Houses tend to be compartmentalized by interior partitions and if doors are closed between rooms the house will have several linked interior zones. If this study focused on predicting heat and air movement for individual rooms, then this would be a concern, but when determining overall values for the whole house, the single zone approach is adequate. In addition, the extra information on the flow resistance of all the flow pathways between all the rooms of the house is almost impossible to determine, so the required input information for a more complex model is generally unknown. One significant aspect of the single zone assumption is that it ignores heat transfer through the ducts that is transported by air flow through the ducts from room-to-room when the air handler is off. This is generally not a problem for this study because it is a very small part of the load for the whole house. Some simple calculations show that the room-to-room flows through attic ducts contribute less than $100 \mathrm{~W}$ to the house load. Note that REGCAP does include air flows (and the associated heat transfer) between the house and the attic through the duct leaks when the air handler system is off.

The equipment model (Proctor (1999)) for REGCAP is based on manufacturers' performance data. The capacity and power consumption change with the outside weather conditions, flow rate across the evaporator coil, and the return air conditions. Additional information regarding air conditioner performance changes due to incorrect system charge and system air flow have been adapted from laboratory data (Rodriguez et al. (1995)). The output from the airflow and thermal models are used together with weather data to determine the air conditioner performance. For example, the capacity of the air conditioner is decreased as the outdoor temperature increases, and refrigerant charge and air flow across the evaporator decrease. The temperature change across the evaporator coil is determined from the volumetric flow rate through the coil (the system fan flow) and the calculated capacity of the equipment. Due to the limited data available and the possible changes in equipment performance for specific air conditioner equipment, the equipment performance algorithms are as simple as possible and assume that the various effects combine independently. Field measurements on houses with a range of systems in different climates have been used to verify the predictive ability of the equipment model (Siegel et al. (2000)). For the verification studies, the measured system thermostat switch points were used in order to avoid differences in the real and modeled thermostat performance. For the simulations, the thermostat model is a simple on/off setpoint with a deadband of $\pm 1{ }^{\circ} \mathrm{C}$.

The thermal model uses a lumped heat capacity approach in which the attic, house and HVAC system are split into 16 nodes (plus the outside conditions and the equipment capacity). These nodes are illustrated in Figure 1. Heat is transferred between the nodes by air motion (for the air nodes), convection (between air and surfaces), radiation (between surfaces in the attic, solar effects and night time exterior surface cooling) and conduction (between nodes in contact with each other). REGCAP uses gaussian elimination on the set of energy balance equations for each node to determine the node temperatures.

The attic is modeled as a gable-ended structure with two pitched roof decks plus gable ends. The two separate surfaces are used to allow for differential solar heating depending on roof orientation. To reduce the input data burden, REGCAP uses simple correlations based on field measurements in attics to correlate the attic floor area and roof pitch to determine the geometry used in the attic heat transfer calculations and the thermal mass of the attic wood. REGCAP uses a simple single node/zone model for estimating house loads because the model is focused on 
HVAC system performance rather than building envelope performance. In addition, without detailed house and site information, a more complex house thermal model was not justifiable. Future work will include more sophisticated models of house performance that focus on the coupling to the thermal mass of the house structure.

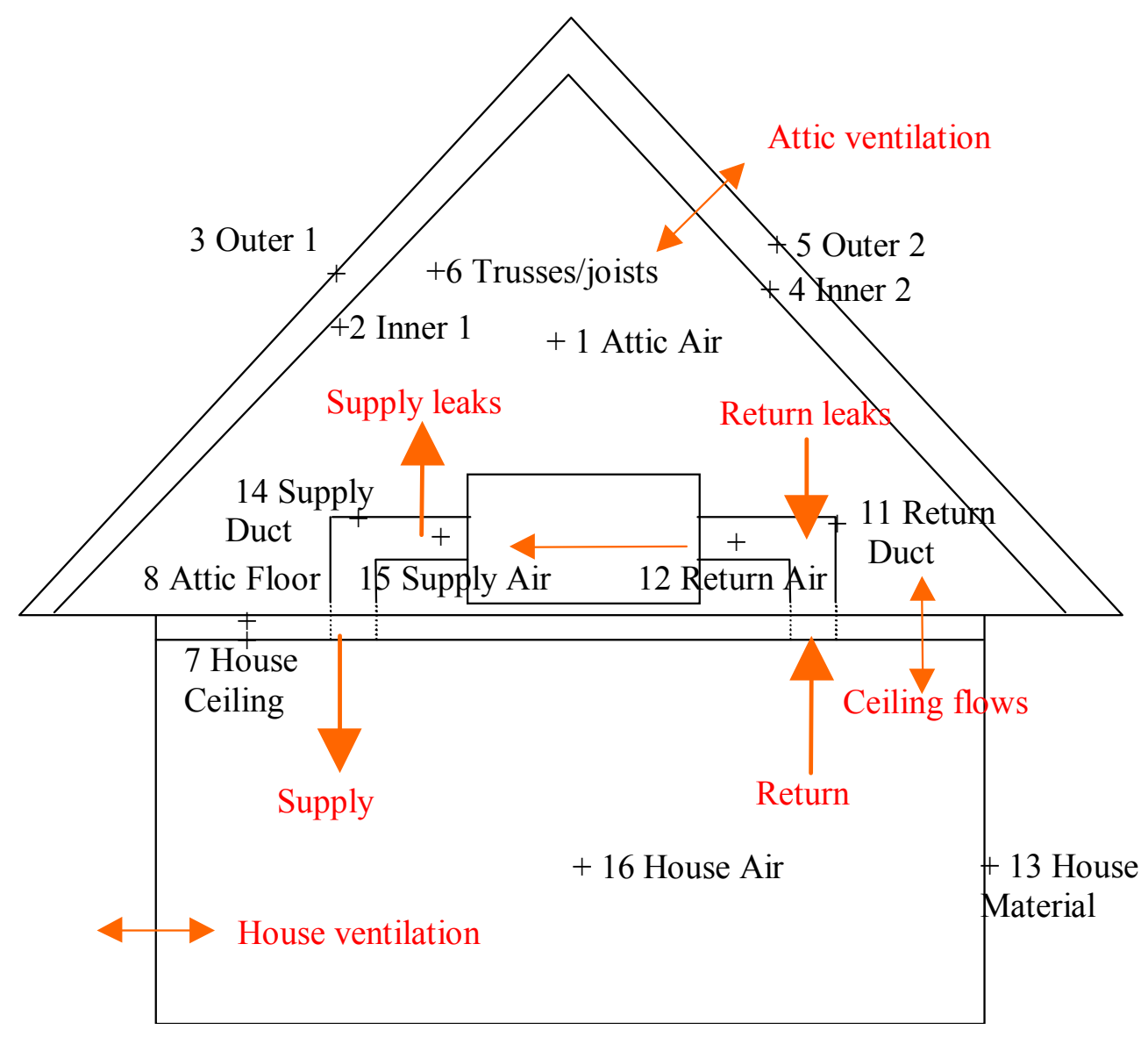

Figure 1. Nodes for thermal model

The model is able to use single nodes for the supply and return duct branches because all the supply and all the return ducts are in the same space: the attic. If some ducts were in other locations (e.g., a crawlspace) then additional nodes would be required to account for heat transfer to these other spaces. The use of a single node per duct location is not a large source of uncertainty because the temperature changes within the supply or return ducts are smaller than the other temperature differences active in the heat transfer calculations. As the verification results show, a single modeled supply air temperature is very close to the average of the measured supply temperatures. This single node approach for separate supply and return ducts has also been successfully used by other researchers and thermal distribution system experts, e.g., ECOTOPE (1997) and in a draft ASHRAE Standard for thermal distribution system efficiency (ASHRAE Standard 152P (2001)).

In order to investigate the effects of system cycling, equipment capacity and alternative thermostat settings, the timestep for the simulations in this study was set to one minute. Parametric tests showed that shorter timesteps produce too much computational burden for no significant improvement in time response and longer timesteps are too coarse to differentiate the detailed system performance changes (e.g., the changes in cyclic behavior for reduced capacity systems).

The attic surfaces experience both natural and forced convection. The forced convection is based on empirical relations developed from standard Nusselt relationships and linearized (by Ford (1982)) over the range of temperatures seen in residential buildings. The velocities for exterior surfaces are based on the exterior wind speed at eave height. The interior velocities are based on the ventilation air flows and the size of holes through which the ventilation air passes. This assumption for interior velocities is physically more realistic and gives higher velocities 
for attic interior surfaces than the traditional plug flow assumption used by Ford (1982) and Burch and Luna (1980). The natural convection coefficient uses the same length scale as for forced convection and a standard Nusselt relationship (Holman (1981)). Fortunately, changes in the heat transfer coefficient due to surface orientation do not significantly affect the attic heat transfer and a coefficient based on a single orientation (taken from Fuji and Imura (1972)) can be used. The total heat transfer coefficient is determined from the cube root of the sum of the forced and natural heat transfer coefficients cubed. This makes the larger of the two coefficients most dominant, while maintaining a smooth transition from one to the other. For the house the internal convection heat transfer coefficient is fixed at $7 \mathrm{~W} / \mathrm{m}^{2} \mathrm{~K}$. This value is based on the correlation given in ASHRAE Fundamentals, Chapter 3 (ASHRAE (1997)) that is not very sensitive to internal air flow velocities. Details of additional simplifying assumptions in REGCAP are given in Appendix 1.

The general input data requirements for REGCAP are:

DUCTS: surface area, location, leakage, insulation, register and air handler flows

EQUIPMENT: manufacturers performance data, refrigerant charge, and evaporator airflow

ENVELOPE: leakage, thermal properties

CLIMATE: Temperature, windspeed and direction, humidity ratio, solar radiation

The REGCAP output includes:

DUCTS: energy flows at the registers and losses to unconditioned space

EQUIPMENT: operating condition capacity and efficiency

ENVELOPE: Thermal losses and ventilation flows

The simulations were run for 24 hour periods corresponding to a design day and a peak day. The design day is the day most like the design conditions. There are many definitions of peak operating conditions. In this study, the peak day is the hottest (for cooling) or coldest (for heating) day of the year. The heating calculations were run for 36 hours. The additional 12 hours for heating allows for a full night of simulations to be run (when heating loads are highest).

\section{COMPARISON BETWEEN MEASURED DATA AND REGCAP SIMULATIONS}

To validate the REGCAP simulations, this study used measured data from three different sites: Palm Springs, Sacramento and Las Vegas. These homes have an average floor area of $1500 \mathrm{ft}^{2}\left(140 \mathrm{~m}^{2}\right)$ and have ducts located in the attic. Other houses used previously to validate REGCAP have cathedralized attics and are discussed in Seigel et al. 2000. The validation measurements consisted of diagnostic tests to characterize the house and duct system combined with several days of continuous measurement of air temperatures and relative humidities, power consumption and weather data. The diagnostic tests included: envelope leakage, duct leakage, register air flows, air handler air flows, refrigerant charge, duct surface area, and other data required as model input (e.g., equipment capacity and efficiency ratings). The continuous measurements included energy flows at each register and between the return and supply plenum (based on temperature and relative humidity), temperature and relative humidity in each room, the duct location(s) and outside, direct and diffuse solar radiation, wind speed, wind direction, power consumption of equipment and house infiltration rate (using a constant injection tracer gas system). The houses were operated so that the cooling equipment was not turned on until about 3:00 p.m. with the house (and duct system) heating up during the day. This mode of operation is a popular method of reducing energy costs by not conditioning the house when there are no occupants during the day and then having the air conditioner pull down the interior temperature to the desired indoor temperature in the afternoon before the occupants return to the house. This mode of operation tests the ability of REGCAP to predict highly dynamic HVAC system and house performance.

The comparisons between measured and predicted results focus on the house, attic, supply, and return air temperatures. In general, REGCAP gives temperatures close to the measured values (typically within $\pm 2{ }^{\circ} \mathrm{C}( \pm$ $\left.3.6^{\circ} \mathrm{F}\right)$ ). The equipment model predicts capacity very closely for all sites (within $4 \%$ of measured values), but tends to uniformly underpredict the power consumption by about $10 \%$. The differences between measured and predicted values are mainly due to model simplifications and do not significantly change the building load or the predicted HVAC system performance. 
House temperature: The average absolute difference between the predicted and the measured data is different from simulation to simulation, but in most houses it was in the range of 1 to $2^{\circ} \mathrm{C}\left(2\right.$ to $\left.4^{\circ} \mathrm{F}\right)$. Observations of the many simulation results and some additional parametric work have shown that these differences are mainly due to two of the REGCAP assumptions for the house thermal model. Firstly, the coupling between the house thermal mass and the house air is significant and not modeled with sufficient sophistication (The simulation results show that the house thermal mass may be too high.). Secondly, the effects of solar radiation may be under predicted. Unfortunately, there is no simple method of dealing with these problems at present, however, future work will concentrate on these issues. An example comparison is shown in Figure 2.

There are high peak house air temperatures in the simulation results when the air conditioner first turns on. These peaks are due to the hot air in the ducts being blown into the house. This peak does not appear in measured data because of several issues. First, when the air handler is off, the predicted supply air temperature is higher than the measured supply air temperature. So, when the air handler turns on, the predicted temperature of air blown in to the house is too high. For the measured data, the peak is also reduced because the measured data is a five minute time average. Additional simulations with five minute time step have shown that this peak does not appear with longer averaging times, however the five minute time step leads to unacceptable compromises in estimates of cyclic or dynamic effects.

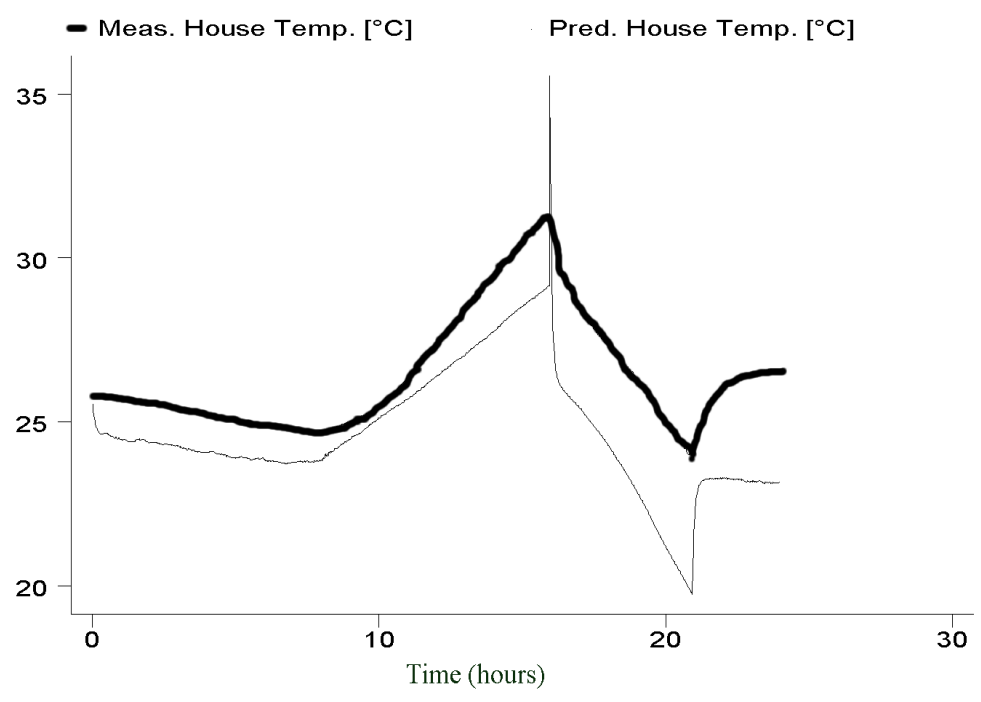

House

\section{Figure 2: Comparison measured and predicted house temperature}

Attic temperature: The simulation results show average differences of about $3^{\circ} \mathrm{C}\left(5.4^{\circ} \mathrm{F}\right)$ between measured and predicted temperature. This is a reasonable difference given the highly variable attic temperatures because it is only about $7 \%$ of the $40 \mathrm{~K}$ attic temperature swing. The simulations are good at reproducing the large diurnal fluctuations in attic temperatures, as shown in Figure 3. The main reasons for the temperature differences are poor estimates of exterior radiation effects (solar gains during the day and radiative cooling at night). This hypothesis is confirmed by the study of other sites for which measured data are lower than predicted data in the morning before sunrise and the opposite happens once the sun shines. Factors such as the emissivity, the absorptivity of the roof material or the amount of cloud cover are not perfectly known and this uncertainty in model input contributes to these differences. 


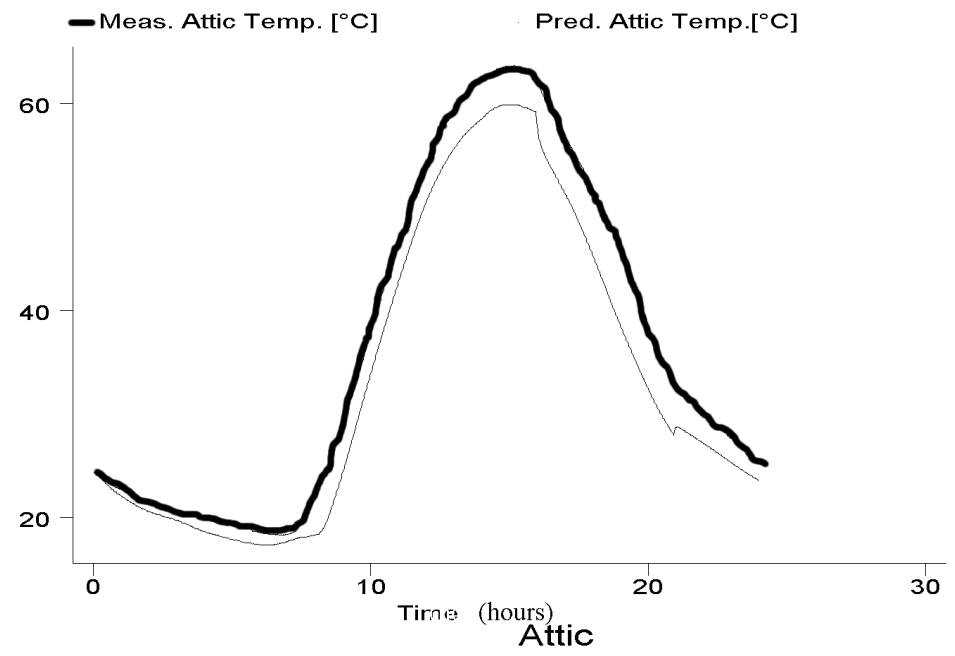

Figure 3: Comparison Measured and predicted Attic temperature

The simulations and measured data show similar variations in attic temperature due to duct system operation (as shown in Figure 4). As the system cycles it cools the attic air when the cooling system is on. The attic air then warms up when the system is off. This cycling shows how the duct losses are conditioning the attic rather than the house. A system with no duct losses would not show this cycling of attic temperature.

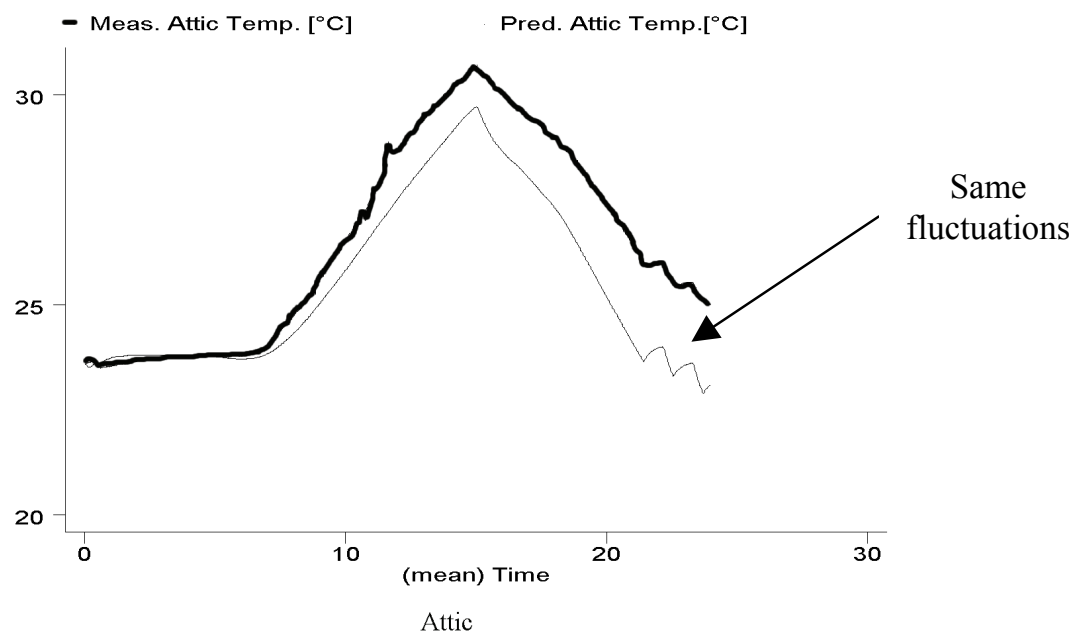

Figure 4: Comparison measured and predicted return air temperature

Return Duct air: As shown in Figure 5, the return duct air temperature agreement is very good when the air handler is on. The return duct air temperature is close to indoor conditions and is dominated by the indoor air flow into the return due to air handler operation. When the air handler is off, the predicted temperatures are higher than the measured results. 


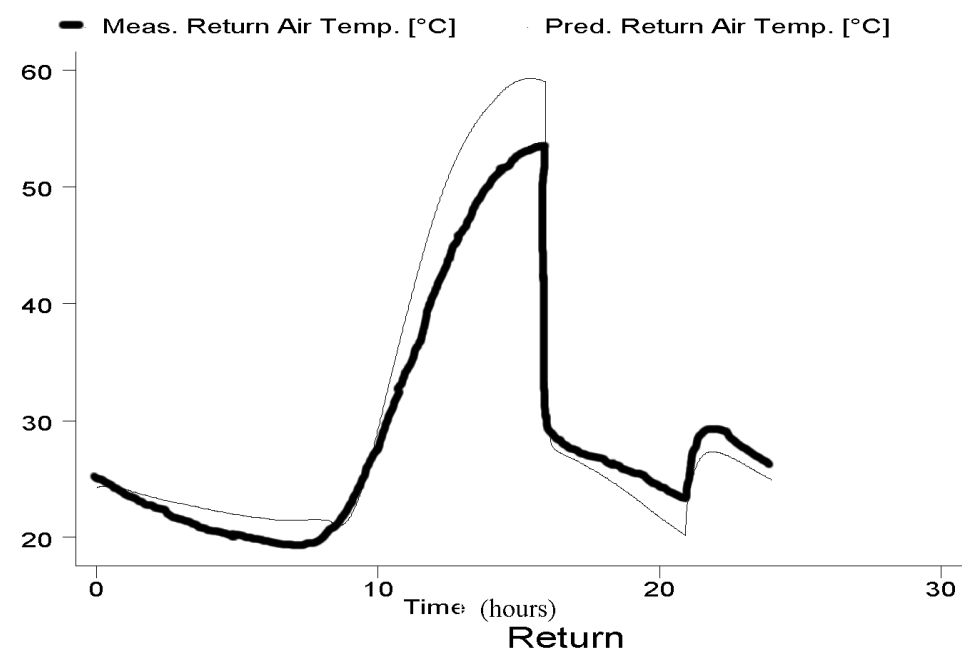

Figure 5: Comparison measured and predicted return air temperature

Supply duct air: Figure 6 shows that the Supply duct air has the same behavior as return duct air, with good agreement when the air handler is on but not when it is off. The high temperatures for the supply and return duct simulations with the air handler off are due to strong coupling to the hot attic air temperature and radiation exchange with the interior attic surfaces. In addition, any air flows from room-to-room through ducts when the air handler is off will cool the duct air and these multi-zone effects are not taken into account in the simulation. REGCAP only calculates the flow of air passing from the attic to the house or from the house to the attic through duct and ceiling leaks. It should be noted that these errors when the air handler is off do not affect the results when the air handler turns on, and do not have a significant effect on the overall building load or system losses. With the air handler on, the heat transfer is dominated by the air handler flows and equipment operation.

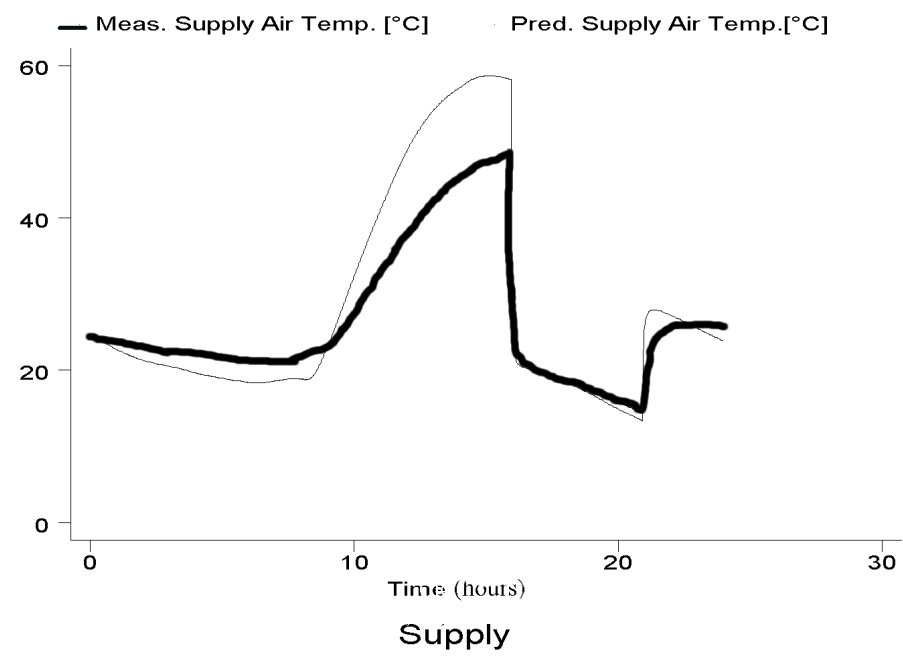

Figure 6: Comparison measured and predicted supply air temperature

Power consumption: In most cases, measured data were about $300 \mathrm{~W}$ greater than predicted data, or about $10 \%$ of the total power consumption. Detailed investigations have shown that this is a result of the equipment model under predicting the actual power consumption. We are continuing to develop the equipment model to reduce these effects. 


\section{WEATHER DATA AND HOUSE/SYSTEM FEATURES}

\section{Climate}

Cooling simulations were run minute-by-minute for 24 hour periods corresponding to a design day. Weather data for a whole year were searched for a day that represented a design day $(99 \% / 1 \%$ design conditions from ASHRAE Fundamentals (1997)). The heating simulations were run for 36 hours. The additional 12 hours allow a full night of simulations (when heating loads are highest). The input weather data were the hourly weather data developed by the California Energy Commission for use in residential energy calculations (CEC (1998)). These weather data include all 16 climate Zones for the state of California. These climate zones are illustrated in Appendix 2. The cooling system simulations were performed for climate zones 8 to 15 because other zones do not require residential cooling. The heating system simulations were performed for all of the 16 climate zones. The hourly weather data include the solar radiation, outdoor temperature, outdoor humidity ratio, wind speed, wind direction and the atmospheric pressure. The one-hour data were linearly interpolated down to one minute for the simulations. The hourly weather data includes the solar radiation, outdoor temperature, outdoor humidity ratio, wind speed, wind direction and the atmospheric pressure. The one-hour data was linearly interpolated down to one minute for input to the simulations.

For each climate zone, the altitude, latitude, and day of the year are required because the solar radiation calculations require this information. The average altitude of each climate zone was taken from The Atlas of California (1979). The latitude was determined approximately using a map of California. The altitude and latitude used in the simulations are summarized in Appendix 3.

Two days were selected from each year of data for both heating and cooling. One day is for the peak demand for the coolest or the hottest day of the year. This peak day has the maximum number of hours at the peak temperature. Usually there were several days with the same peak temperature for at least an hour, so we chose the day with the most hours at the peak temperature. The second day corresponds to the day most like design conditions ( $1 \%$ of the year). In this case we picked the day with the most hours at or near the summer (for cooling) or winter (for heating) design temperature (from ASHRAE 1997). Appendix 4 gives the peak and design day information for each climate zone.

\section{House and System features}

The house used in the simulations is based the standard California house used in California State Energy Code compliance calculations, known as Title 24 (CEC 1998). Additional house characteristics required for the simulations (e.g., leakage distribution in walls) were estimated based on previous simulation work and measurements made in California houses by LBNL and other researchers. The characteristics of the house including leakage and thermal properties are summarized in Table 1. The CEC standard house has two eave heights but REGCAP only uses the higher one (it is used in REGCAP to determine the wind velocity corrections). The plan and dimensions of the house are illustrated in Appendix 6. The attic properties are described in Table 2, and the base case duct system characteristics are summarized in Table 3. 
Table 1: House Description

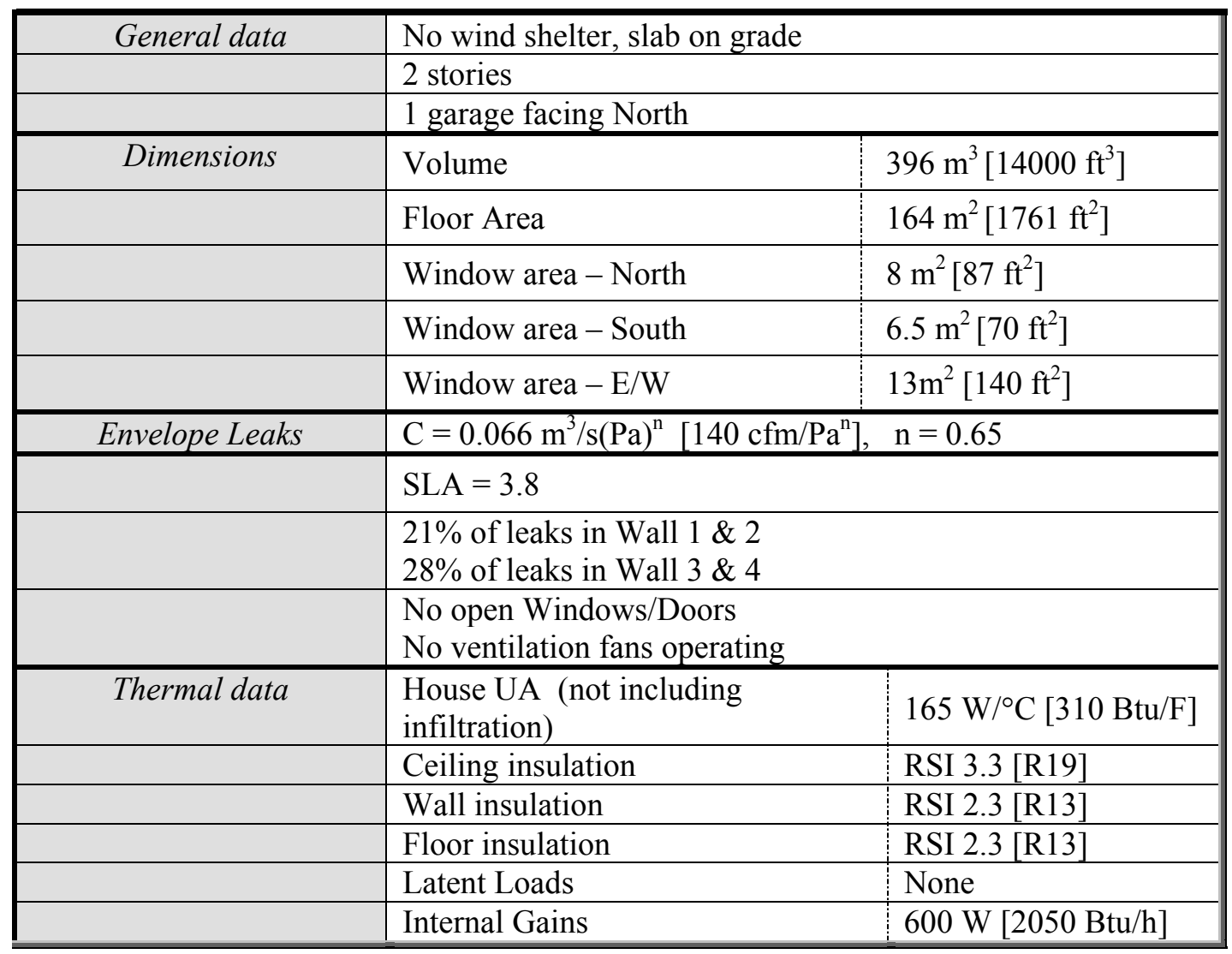

Table 2: Description of Attic Characteristics

\begin{tabular}{|c|l:l|}
\hline General data & Volume & $62 \mathrm{~m}^{3}\left[2190 \mathrm{ft}^{3}\right]$ \\
\hline & Area & $78 \mathrm{~m}^{2}\left[836 \mathrm{ft}^{2}\right]$ \\
\hline Roof & Asphalt shingle \\
\hline & Roof Ridge perpendicular to front of the house \\
\hline & Roof Pitch & $25.5^{\circ}$ \\
\hline & Height of Roof Peak & $6.5 \mathrm{~m}[21.25 \mathrm{ft}]$ \\
\hline & Soffit Height & $5 \mathrm{~m}[16 \mathrm{ft}]$ \\
\hline Leakage Data & $\mathrm{C}=0.236 \mathrm{~m}^{3} / \mathrm{sPa}^{\mathrm{n}}\left[500 \mathrm{cfm} / \mathrm{Pa}^{\mathrm{n}}\right] ; \mathrm{n}=0.51$ \\
\hline & ELA $=0.185 \mathrm{~m}^{2}\left[2 \mathrm{ft}^{2}\right]$ & \\
\hline & Soffits are $20 \%$ of total leakage \\
\hline & No additional vents or ventilation fans \\
\hline
\end{tabular}


Table 3: Base case duct features

\begin{tabular}{|c|c|c|c|}
\hline \multirow[t]{3}{*}{ General data } & \multicolumn{3}{|l|}{ Located in the attic } \\
\hline & \multicolumn{3}{|l|}{ Insulated plastic flex } \\
\hline & & Supply & Return \\
\hline \multirow[t]{2}{*}{ Dimension } & Diameter (mean) & $0.25 \mathrm{~m} \mathrm{[10 \textrm {in } ]}$ & $0.5 \mathrm{~m} \mathrm{[20} \mathrm{in]}$ \\
\hline & Length & $38.7 \mathrm{~m}[127 \mathrm{ft}]$ & $5.1 \mathrm{~m}[16.8 \mathrm{ft}]$ \\
\hline \multirow[t]{3}{*}{ Leakage data } & Leakage (fraction of fan flow) & $11 \%$ & $11 \%$ \\
\hline & Exponent & 0.6 & 0.6 \\
\hline & Coefficient & $\begin{array}{l}0.01 \mathrm{~m}^{3} \mathrm{~s} / \mathrm{Pa}^{\mathrm{n}} \\
{\left[21 \mathrm{cfm} / \mathrm{Pa}^{\mathrm{n}}\right]}\end{array}$ & $\begin{array}{l}0.01 \mathrm{~m}^{3} \mathrm{~s} / \mathrm{Pa}^{\mathrm{n}} \\
{\left[21 \mathrm{cfm} / \mathrm{Pa}^{\mathrm{n}}\right]}\end{array}$ \\
\hline \multirow[t]{2}{*}{ Thermal data } & Insulation thickness & $0.04 \mathrm{~m}[1.5 \mathrm{in}]$ & $0.04 \mathrm{~m}[1.5 \mathrm{in}]$ \\
\hline & $\mathrm{R}$ value & RSI 0.7 [R 4.2] & RSI 0.7 [R 4.2] \\
\hline
\end{tabular}

* - Details of the duct leakage coefficient calculations are given in Appendix 7.

Four systems were simulated for this study that were developed in order to cover a wide range of possible HVAC system performance. The following system characteristics are based on the results of many field investigations, some of which are referred to explicitly here:

- Base case - This case describes an average new house in California, with duct leakage of $22 \%$ of air handler flow split evenly between supply and return ducts (Walker et al. (1998), Modera and Wilcox (1995), and CEC (1998)), 85\% of correct refrigerant charge and air handler flow (Blasnik et al. (1996) and Proctor (1997), duct surface area of $27 \%$ of floor area (Walker (1998)), nominal R4 duct insulation, and a 4 ton air conditioner. Air conditioner sizing was based on field surveys and a contractors rule of thumb of about 1 ton of air conditioner capacity for every $500 \mathrm{ft}^{2}$ of floor area (Brown et al. 1994; Proctor et. al. 1995; Proctor \& Albright 1996; Vieira et al. 1996).

- Poor case - this case describes a below-average house in California. Duct leakage is increased to 28\% (Jump et al. (1996)) and charge reduced to 70\% (Blasnik (1996) and Proctor (1997)) of their nominal values.

- Good case - this case describes an average new house in California that has been improved by duct sealing to $6 \%$ duct leakage the specification for energy efficient duct credits in the California State energy code (Title 24), refrigerant charge and air handler flow correction. The air conditioner capacity has not been changed.

- Good resized - this is the best case with a properly sized air conditioner according to Manual $J$ and Manual $S$ (ACCA $(1986,1992)$ ). For cooling, this system has one ton less capacity and for heating the capacity reduction is also $25 \%$. The air flow and duct surface area were correspondingly reduced by $25 \%$. For resized heating systems, the furnace capacities were reduced by $25 \%$ and $50 \%$ depending on duct location.

Two duct locations were simulated, with the ducts either located in the attic or in the conditioned space. In both cases the ducts were completely within each space, however REGCAP does have the capability to place any fraction of the ducts (and their leakage) in each space. The setpoint temperatures and schedule, that are based on California norms, are those given by Title 24 (CEC 1998).

Three thermostat strategies were used in the cooling simulation:

- $\quad 1$ setpoint: with a constant temperature during all the day of $25.5^{\circ} \mathrm{C}\left(78^{\circ} \mathrm{F}\right)$.

- $\quad 2$ setpoints: The system is off from 9:00 a.m. to 3 p.m. (3 p.m. is used because time is needed to cool down the house before people come back at home after work at 5:00 p.m.). This strategy is used to save energy by not operating air conditioning when the house is unoccupied. There was no specific setback temperature for cooling, instead the system was not turned on at all during the day until 3:00 p.m.

- $\quad 3$ setpoints: in this case, the air conditioning operates from 7 a.m. to 9 a.m. and 5 p.m. to 10 p.m.

For heating, only two thermostat strategies are considered:

- 1 setpoint: with a constant setpoint of $20^{\circ} \mathrm{C}\left(68^{\circ} \mathrm{F}\right)$.

- 2 setpoints: the setpoint is $20^{\circ} \mathrm{C}\left(68^{\circ} \mathrm{F}\right)$ from 8 a.m. to 12 p.m., and $15.5^{\circ} \mathrm{C}\left(60^{\circ} \mathrm{F}\right)$ the rest of the time. 


\section{SIMULATIONS}

REGCAP was designed to answer questions about the effect of heating and cooling system inefficiencies on system performance. Specifically, the goals of this research were to answer the following questions:

1. What are the energy and comfort penalties associated with inefficient heating and cooling systems in California climates?

2. How much does correcting those efficiencies improve system performance?

3. What are the performance changes associated with downsizing equipment?

These questions were answered by evaluating the following energy and comfort performance parameters.

This study evaluates the energy related issues of system performance by evaluating duct efficiency, equipment efficiency, total HVAC efficiency, peak power and total energy. The peak power consumption includes both air handler motor and compressor power. The total energy represents the energy consumed during the 24-hour period simulation. A key parameter is the power delivered to the conditioned space via the register, and is called Tons At the Register (TAR) (although this is a misnomer for heating systems, it is retained for convenience). Higher TAR implies more energy delivered to the conditioned space. TAR is calculated using the following formula:

$$
\mathrm{TAR}=\left(\mathrm{m}_{\text {ah }}-\mathrm{m}_{\text {supleak }}\right) \mathrm{C}_{\mathrm{p}}\left(\mathrm{T}_{\text {house }}-\mathrm{T}_{\text {supair }}\right)
$$

Where $\mathrm{m}_{\mathrm{ah}}=$ mass flow at the air handler $(\mathrm{kg} / \mathrm{s}(\mathrm{lb} / \mathrm{s}))$,

$\mathrm{m}_{\text {supleak }}=$ mass flow of leakage from the supply ducts $(\mathrm{kg} / \mathrm{s}(\mathrm{lb} / \mathrm{s}))$,

$\mathrm{C}_{\mathrm{p}}=$ specific heat of air $(\mathrm{kJ} / \mathrm{kgK}(\mathrm{Btu} / \mathrm{lbR}))$,

$\mathrm{T}_{\text {house }}=$ temperature of the house air $(\mathrm{K}(\mathrm{R}))$,

$\mathrm{T}_{\text {supair }}=$ temperature of the supply air entering in the house (K (R )).

Three efficiencies are defined as follows:

Equipment efficiency $=$ Equipment Output Capacity / Power Consumption

Duct efficiency $=\mathrm{TAR} /$ Equipment Output Capacity

Total HVAC efficiency $=\mathrm{TAR} /$ Power Consumption

The three comfort related issues studied are: pulldown time, Tons At the Register (TAR) and time above the setpoint. A common operating strategy used to reduce energy consumption is to turn off the air conditioning system during the day when the house is unoccupied. The pulldown time is the time required to cool the house after it has heated up during the day. A short pulldown time means that the house is comfortable sooner, which is desirable for the occupants. In these simulations, the deadband on the thermostat to turn the system on and off is $\pm 1{ }^{\circ} \mathrm{C}\left(2^{\circ} \mathrm{F}\right)$, therefore the pulldown time is defined as the time it takes to cool to the setpoint minus $1^{\circ} \mathrm{C}\left(2^{\circ} \mathrm{F}\right)$. TAR is used as a comfort parameter because it changes the occupants perception of cooling system performance and also effects consumer expectations of how much heating or cooling the system should provide (as discussed further in Walker et al. 1998). The simulations track the amount of time the house temperature is above the setpoint for the single setpoint thermostat strategy. This time is also a comfort indicator because a house that cannot be temperature controlled will be too hot for the occupants. It is of key importance for systems that have high losses and cannot meet the building load. The system does not cycle and the indoor temperature rises above the setpoint at the hottest part of the day.

\section{Cooling System Specifications}

A total of 368 simulations were performed based on the combinations of climate, duct location, system description and thermostat operation. In addition to the parameters that identify the four cases, the following were also changed and are summarized in Table 4. 
- When ducts are located in the conditioned space, $0 \%$ leakage is assumed. The exception is when base case systems are moved into conditioned space where $6 \%$ of leakage is used (based on measurements reported in Siegel et al. (2000)).

- Unbalanced leaks will be tested for the base case by using $7 \%$ or $15 \%$ (the same total leakage) for the supply and the return leakage respectively. The imbalances change house and attic ventilation as well as duct system losses.

- Airflow across the cooling coil changes depending on the case. $0.046 \mathrm{~m}^{3} / \mathrm{s} / \mathrm{kW}$ ( $340 \mathrm{cfm} / \mathrm{ton}$ ) is used for the poor and base cases and $0.054 \mathrm{~m}^{3} / \mathrm{s} / \mathrm{kW}(400 \mathrm{cfm} / \mathrm{ton})$ is used for the good and good resized cases. $0.054 \mathrm{~m}^{3} / \mathrm{s} / \mathrm{kW}(400 \mathrm{cfm} / \mathrm{ton})$ is middle of manufacturers recommended range (between $0.041 \mathrm{~m}^{3} / \mathrm{s} / \mathrm{kW}$ (300 cfm/ton) and $0.068 \mathrm{~m}^{3} / \mathrm{s} / \mathrm{kW}(500 \mathrm{cfm} / \mathrm{ton})$. Lower flow leads to lower equipment efficiency, and greater conduction losses (because air takes longer to travel from the plenum to the register).

- Two values of the Energy-Efficiency Ratio (EER) are used: 9.5 and 9.3 because this study used explicit performance data for specific equipment.

- The air handler power consumption is $700 \mathrm{~W}(2.4 \mathrm{kBtu} / \mathrm{h}), 600 \mathrm{~W}(2.1 \mathrm{kBtu} / \mathrm{h})$ or $500 \mathrm{~W}(1.75 \mathrm{kBtu} / \mathrm{h})$ depending on the airflow of the system (higher airflows requiring higher air handler power).

- Three levels of duct insulation are used: RSI 0.75, 1.05 and 1.4 (R4.2, R6 and R8).

Table 4: Summary of cooling systems parameters

\begin{tabular}{|c|c|c|c|c|c|c|c|c|c|c|c|}
\hline \multirow[t]{2}{*}{ System } & \multirow{2}{*}{$\begin{array}{c}\text { System } \\
\text { charge } \\
\%\end{array}$} & \multirow{2}{*}{$\begin{array}{c}\text { Air Handler } \\
\text { flow } \\
\mathbf{m}^{3} / \mathbf{s} / \mathbf{k W} \\
\text { (cfm/Ton) }\end{array}$} & \multicolumn{2}{|c|}{$\begin{array}{l}\text { Duct Leakage } \\
\text { Fraction }\end{array}$} & \multirow{2}{*}{$\begin{array}{c}\text { ARI } \\
\mathbf{k W} \\
\text { (kBtu/h) }\end{array}$} & \multirow[t]{2}{*}{ EER } & \multirow{2}{*}{$\begin{array}{c}\text { Fan } \\
\text { Capacity } \\
\mathbf{W} \\
(\mathbf{k B t u} / \mathbf{h})\end{array}$} & \multirow{2}{*}{$\begin{array}{c}\text { Nominal } \\
\text { Capacity } \\
\text { Tons }\end{array}$} & \multirow[t]{2}{*}{ Insulation } & \multicolumn{2}{|c|}{ Duct Surface Area } \\
\hline & & & $\begin{array}{c}\text { Supply } \\
\mathbf{\%}\end{array}$ & $\begin{array}{c}\text { Return } \\
\%\end{array}$ & & & & & & $\begin{array}{c}\text { Supply } \\
\text { \%Floor } \\
\text { Area }\end{array}$ & $\begin{array}{c}\text { Return } \\
\text { \%Floor } \\
\text { Area }\end{array}$ \\
\hline Base & 85 & $0.046(340)$ & 11 & 11 & $13.5(46)$ & 9.5 & $700(2.4)$ & 4 & $\begin{array}{l}\text { RSI } 0.7 \\
\text { (R4.2) }\end{array}$ & 27 & 10 \\
\hline Poor & 70 & $0.046(340)$ & 14 & 14 & $13.5(46)$ & 9.5 & $700(2.4)$ & 4 & $\begin{array}{l}\text { RSI } 0.7 \\
\text { (R4.2) }\end{array}$ & 27 & 10 \\
\hline Good & 100 & $0.054(400)$ & 3 & 3 & $13.5(46)$ & 9.5 & $700(2.4)$ & 4 & $\begin{array}{l}\text { RSI } 0.7 \\
\text { (R4.2) }\end{array}$ & 27 & 10 \\
\hline $\begin{array}{c}\text { Good } \\
\text { Resized }\end{array}$ & 100 & $0.054(400)$ & 3 & 3 & $10.2(35)$ & 9.3 & $600(2.1)$ & 3 & $\begin{array}{l}\text { RSI } 0.7 \\
\text { (R4.2) }\end{array}$ & 20.3 & 7.5 \\
\hline
\end{tabular}

\section{Heating System Specifications}

A total of 480 simulations were performed based on combinations of climate, duct location, system description and thermostat operation.

The heating capacities were determined from the default in Title 24 (CEC (1998) Chapter 3.8). This default is 105 $\mathrm{W} / \mathrm{m}^{2}\left(34 \mathrm{Btu} / \mathrm{h} / \mathrm{ft}^{2}\right)$ of floor area, which corresponds to about $17.5 \mathrm{~kW}(60 \mathrm{kBtu} / \mathrm{h})$ for the $164 \mathrm{~m}^{2}\left(1761 \mathrm{ft}^{2}\right)$ house. In the simulations, this $17.5 \mathrm{~kW}(60 \mathrm{kBtu} / \mathrm{h})$ default was used and the resized systems used $13 \mathrm{~kW}(45 \mathrm{kBtu} / \mathrm{h})$ for ducts in the attic and $9 \mathrm{~kW}(30 \mathrm{kBtu} / \mathrm{h})$ for ducts in the conditioned space. ACCA manual $\mathrm{J}$ calculations were also performed that showed required capacities about one half of these values. However, to be representative of real systems, the CEC Title 24 standard has been followed. Much of this difference between ACCA R-J and installed capacity is because the same ducts are used for heating and cooling, and the heating equipment capacity is determined in accordance with duct size used for cooling systems. A summary of the ACCA Manual J sizing is given in Appendix 8.

Another parameter has to be taken into account if the HVAC efficiency has to be analyzed: the furnace efficiency. For cooling, the fan and compressor are both electric, and the power consumption is directly related to capacity. But for heating, the air handler fan uses electricity, but the furnace is usually gas fired. For the gas furnace, the efficiency is usually between 0.78 AFUE (Annual Fuel Utilization Efficiency), the minimum DOE federal standard and 0.92 . Oil furnace efficiency is about 0.8 to 0.9 . REGCAP did not include a model for furnace efficiency because it is simply fixed at one of these constant values, and manufacturers rated output capacity was used in the 
calculations. To obtain furnace consumption, the AFUE correction should be applied to the capacities used in this study. Table 5 summarizes the heating system parameters.

\section{Table 5: Summary of Heating system parameters}

\begin{tabular}{|c|c|c|c|c|c|c|c|c|}
\hline \multirow[t]{2}{*}{ SYSTEM } & \multirow{2}{*}{$\begin{array}{c}\text { Air Handler } \\
\text { flow } \\
\mathrm{m}^{3} / \mathrm{s}(\mathrm{cfm})\end{array}$} & \multicolumn{2}{|c|}{$\begin{array}{l}\text { Duct Leakage } \\
\text { Fraction }\end{array}$} & \multirow{2}{*}{$\begin{array}{c}\text { ARI } \\
\text { Capacity, W } \\
(\mathrm{kBtu} / \mathrm{h})\end{array}$} & \multirow{2}{*}{$\begin{array}{c}\text { Air } \\
\text { Handler } \\
\text { Fan } \\
\text { Capacity } \\
\text { W (kBtu/h) }\end{array}$} & \multirow[t]{2}{*}{ Insulation } & \multicolumn{2}{|c|}{ Duct Surface Area } \\
\hline & & $\begin{array}{c}\text { Supply } \\
\%\end{array}$ & $\begin{array}{c}\text { Return } \\
\%\end{array}$ & & & & $\begin{array}{l}\text { Supply } \\
\text { \%Floor } \\
\text { Area }\end{array}$ & $\begin{array}{c}\text { Return } \\
\text { \%Floor } \\
\text { Area }\end{array}$ \\
\hline Base & $0.40(850)$ & 11 & 11 & $17.5(60)$ & 500 & $\begin{array}{l}\text { RSI } 0.7 \\
\text { (R4.2) }\end{array}$ & 27 & 10 \\
\hline Poor & $0.40(850)$ & 14 & 14 & $17.5(60)$ & 500 & $\begin{array}{l}\text { RSI } 0.7 \\
(\mathrm{R} 4.2)\end{array}$ & 27 & 10 \\
\hline Good & $0.47(1000)$ & 3 & 3 & $17.5(60)$ & 500 & $\begin{array}{l}\text { RSI } 0.7 \\
\text { (R4.2) }\end{array}$ & 27 & 10 \\
\hline $\begin{array}{c}\text { Good } \\
\text { Resized }\end{array}$ & $0.35(750)$ & 3 & 3 & $13(45)$ & 375 & $\begin{array}{l}\text { RSI } 0.7 \\
\text { (R4.2) }\end{array}$ & 27 & 10 \\
\hline
\end{tabular}

\section{SIMULATION RESULTS: COOLING}

In the discussion of the cooling simulation results the majority of the discussion and illustrations are for climate zone 8 and climate zone 15, which are respectively the coolest and the hottest climates. Other climate zones give results between these two extremes.

\section{Pulldown Time}

In general, better systems take less time to cool down the house. Poor and base systems are the slowest: typically 1 hour for moderate climates and 5 hours for hot climates. Good systems are the fastest: typically 20 minutes for moderate climates and 3 hours for hot climates. These differences are important for occupants because shorter pulldowns make the house more comfortable during key afternoon and evening hours.

As shown in Figure 7, for moderate climate zones, using a base system or using a good system does not change the pulldown time very much because the pulldown time with a base system is already short. However, for hot climate zones, it makes a significant difference. However, For a base system in climate zone 15, the pulldown times are more than 5.3 hours. With a good system, this value can be reduced to 3.3 hours. In this extreme climate zone, good resized systems do not significantly reduce the pulldown time. These results indicate that resized systems have greater benefit with shorter pulldown times in milder climates, where they require abut half the time of base or poor systems. 


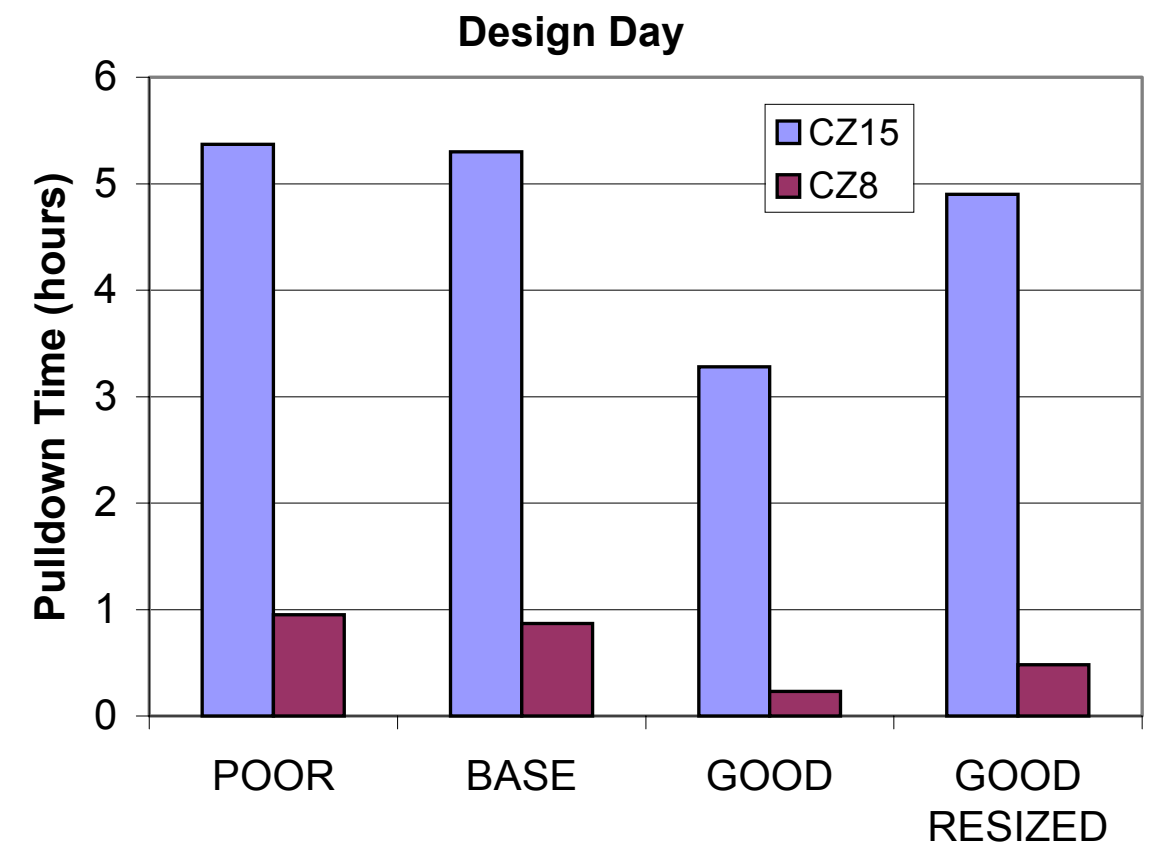

Figure 7: Changes in pulldown time for different climates

\section{Changing the time that the air-conditioning system is turned on}

Rather than determining how long after the system turns on the house is comfortable, a home-owner may operate the system so that the air conditioning is turned on at an appropriate time to have a pleasant house temperature when they return to the house in the evening (between 5 p.m. or at 6 p.m.). Additional REGCAP simulations were performed to determine the turn on times required for climate zone 12 and for the base and good resized systems only in order to reach the setpoint by either 5:00 p.m. or 6:00 p.m. This procedure is iterative because it is not possible to know in advance when to turn a system on to achieve the desired temperature at a fixed time. The results are summarized in Table 6. As expected, good resized systems can be turned on later than base systems. For a design day, compared to the good resized system, only half an hour more is required by the base system to cool down the house temperature. For a peak day, there is a one-hour difference.

Table 6. Required system turn on time to reach the setpoint by a fixed time

\begin{tabular}{|l|c|c|c|c|}
\hline & \multicolumn{2}{|c|}{ Design Day } & \multicolumn{2}{c|}{ Peak day } \\
\hline $\begin{array}{l}\text { Time Setpoint } \\
\text { Reached }\end{array}$ & $\begin{array}{c}\text { BASE } \\
(\mathrm{h}: \mathrm{mm})\end{array}$ & $\begin{array}{c}\text { GOOD RESIZED } \\
(\mathrm{h}: \mathrm{mm})\end{array}$ & $\begin{array}{c}\text { BASE } \\
(\mathrm{h}: \mathrm{mm})\end{array}$ & $\begin{array}{c}\text { GOOD RESIZED } \\
(\mathrm{h}: \mathrm{mm})\end{array}$ \\
\hline 5:00 p.m. & $2: 50$ & $3: 15$ & $1: 15$ & $2: 15$ \\
\hline 6:00 p.m. & $3: 45$ & $4: 15$ & $2: 09$ & $3: 00$ \\
\hline
\end{tabular}

\section{Tons at the register (TAR)}

A good system shows an improvement of about $50 \%$ in TAR compared to a base system for both peak and design day, without increasing the power consumption. As shown in Figure 8, the good system provides the most cooling to the house (highest TAR). The good resized system has higher TAR than the base or poor system, despite its lower equipment capacity. 


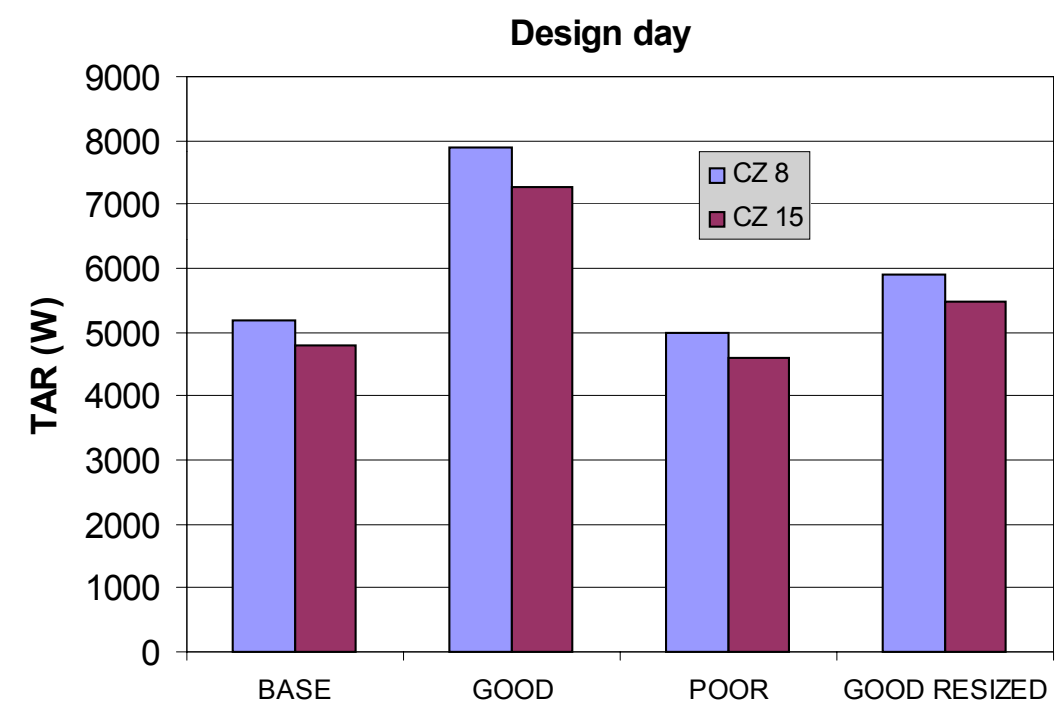

Figure 8: TAR dependence on system capacity and distribution system performance

\section{Cycle length, humidity control and cyclic losses}

Very short cycles can have humidity control problems because the cooling coils need time to cool down below dew point and accumulate enough moisture so that it falls off the coils into the drain pan and thereby flows out of the duct system. With short cycles, coils are not cold enough for long enough to condense moisture, and any moisture that condenses is still on coils at cycle end. This moisture can re-evaporate into air that is blown into the house at the start of the next cycle. Figure 9 illustrates examples of cyclic behavior for a good and a base system. The base system (A and B) has longer air handler cycles than a good system (C and D). However, the air handler cycles for all cases are almost always longer than 10 minutes. Combined with the dry climate in California, none of the tested systems should have humidity control problems. It should be noted that poor systems with long cycles still have poor humidity control due to hot humid outdoor air entering through return leaks combined with low capacity due to the poor refrigerant charge.

Figure 10 shows how the attic temperature responds to the air handler cycles due to the duct system losses to the attic, with the base system changing attic temperatures more than the good system. Good systems lead also to a better indoor temperature control and thus a better comfort than the base system. These systems operate such that the system turns on when the air temperature is $+1^{\circ} \mathrm{C}\left(2^{\circ} \mathrm{F}\right)$ above the setpoint and turns off when the temperature drops $1{ }^{\circ} \mathrm{C}\left(2^{\circ} \mathrm{F}\right)$ below the setpoint due to the $\pm 1^{\circ} \mathrm{C}\left(2^{\circ} \mathrm{F}\right)$ deadband. For the base system (B), the indoor temperature remains almost constant and close to the setpoint temperature $+1^{\circ} \mathrm{C}\left(2^{\circ} \mathrm{F}\right)$ in the afternoon. On the other hand, the good system (D) is able to keep the temperature below the setpoint temperature $+1^{\circ} \mathrm{C}\left(2^{\circ} \mathrm{F}\right)$.

For all the simulations, the maximum indoor temperature is about $1^{\circ} \mathrm{C}\left(1.8^{\circ} \mathrm{F}\right)$ above the highest setpoint. The length of time above the highest setpoint depends on the system and the tons delivered at the register, with the poorer systems spending longer at these high temperatures. The amount of time spent at this high temperature is short (typically 5 minutes) when a base system is used in a moderate climate or a good system is used in a hot climate. The time is much longer (typically 3hours) for a base system used in a hot climate. It should be noted that the "time above the highest setpoint" is not always a simple indicator because in some cases the time can be high because of numerous short cycles (indicating fairly good temperature control) rather than a few longer cycles (e.g., for a good system used in a moderate climate), so it is important to look at the cycle lengths as well as the total time in order to make a judgement about comfortable temperature control. 

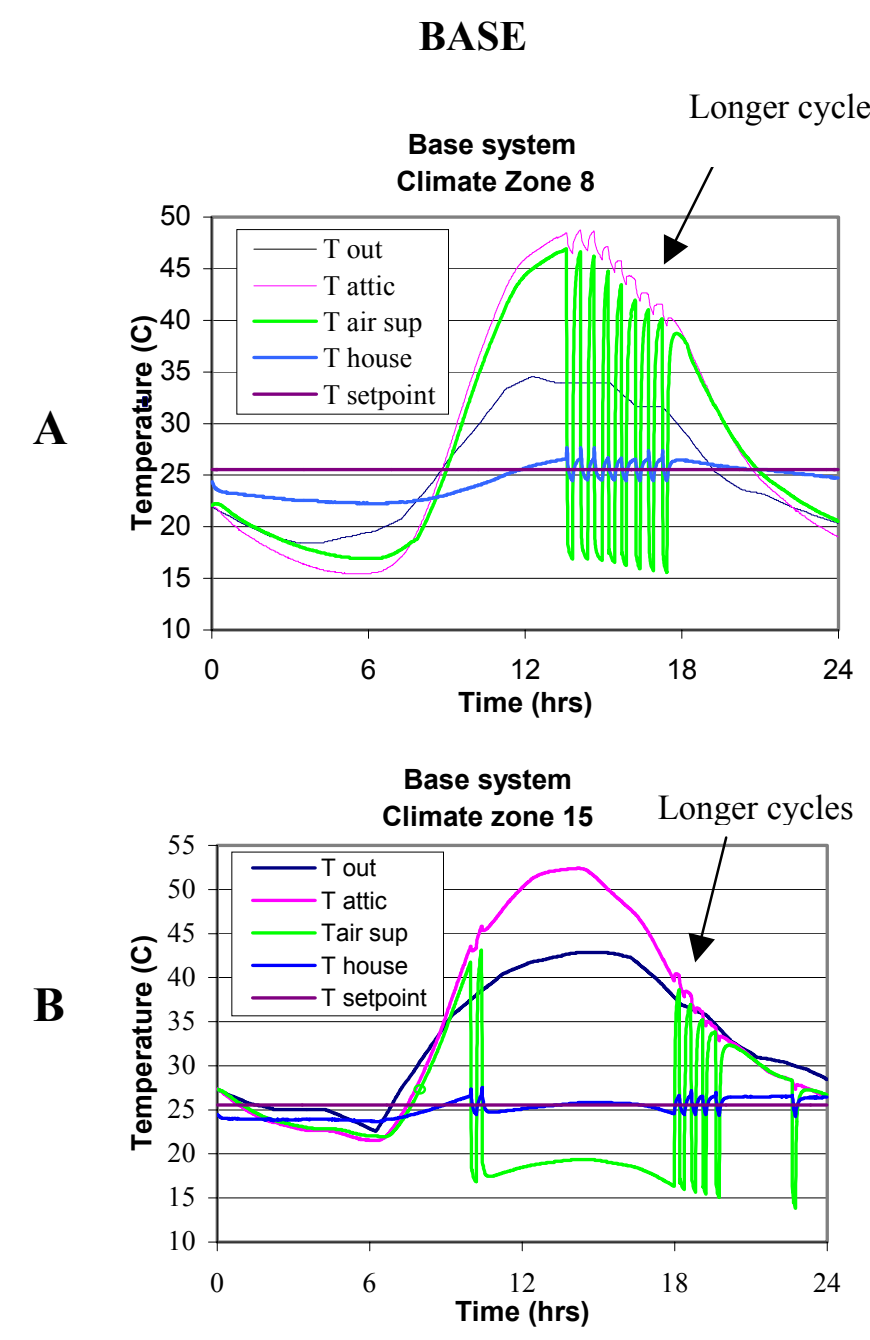

\section{GOOD}
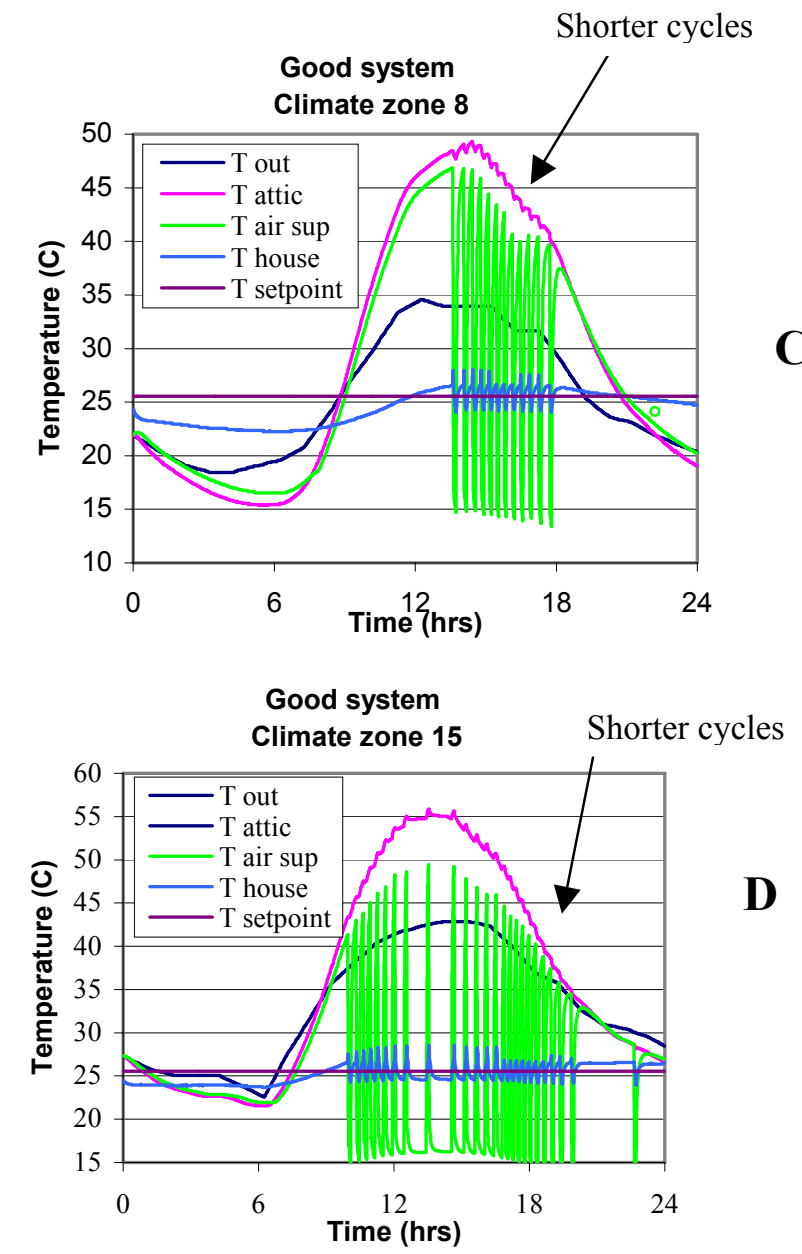

Figure 9: Cycle length comparison between a base and a good system 


\section{Peak demand and power consumption}

The following figures show the duct efficiency, the power consumption and the energy consumption of each system for climate zone 8 and 15 .
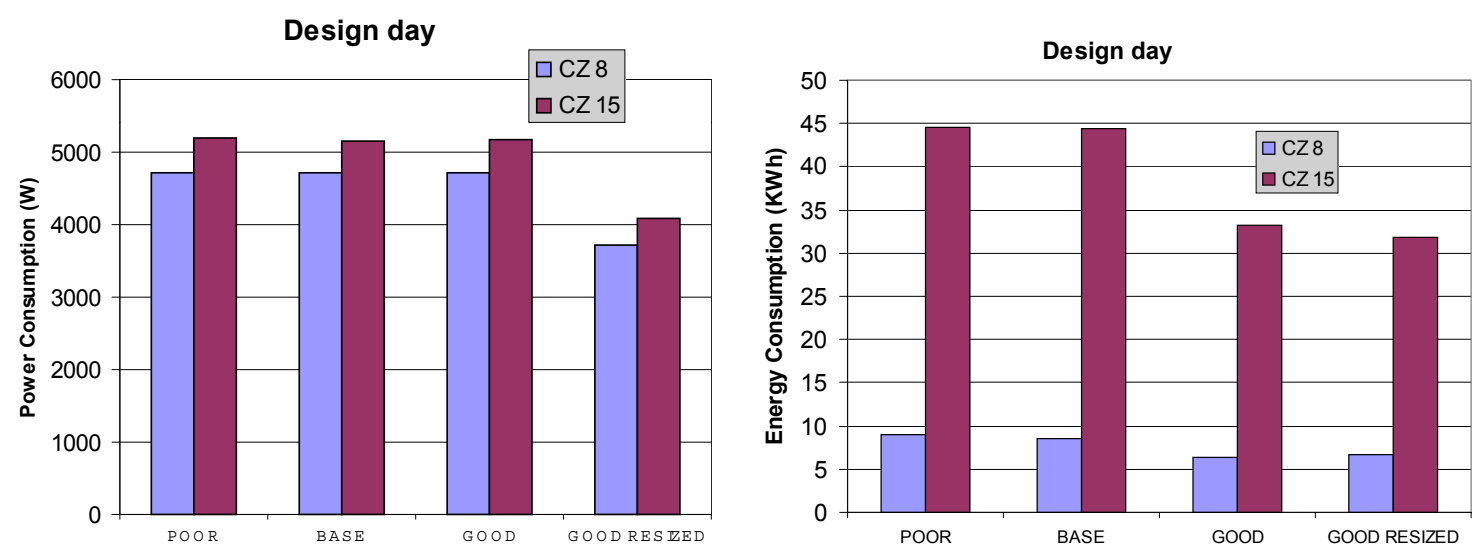

Figure 10: Summary of system performance for a single setpoint thermostat strategy

A good resized system can provide good indoor temperature control and it has $25 \%$ less peak power requirement than the other systems. The climate based power consumption changes are due to higher outdoor temperatures leading to reduced compressor and condenser performance. A good resized system duct efficiency is $25 \%$ greater than the duct efficiency of a base system and its energy consumption is also between $22 \%$ and $28 \%$ lower than a base system. This resized system has less peak demand, less operating cost (less energy used) and less capital cost (cheaper equipment). The poor system consumes the same amount of energy as the base case at design conditions. However, the poor system needs more time to cool down the house and spends more time with elevated indoor temperatures. Both of these effects mean that although the poor system uses the same amount of energy it provides less comfort. To provide the same comfort the poor duct system would require a larger capacity air conditioner that would consume more peak power and more energy.

For unbalanced leakage, the results show different behavior for excess supply leaks compared to excess return leaks. Unbalanced systems with excess supply leaks have $6 \%$ higher duct efficiency than balanced systems with equal total leakage (that have a duct efficiency of 56\%). However, an unbalanced system with excess return leaks has a duct efficiency between $4 \%$ and $10 \%$ lower than balanced systems. The inefficiency of ducts with high leakage at the return is due to the high temperature reached in the attic when the outside temperature is high. In this case, air from the hot attic enters the return ducts and heats the air from the return in the house. The energy required to cool down the mixed air is greater than if all the air came from inside the house and significantly reduces the effective capacity of the system.

This result may imply that the energy consumption will be greater for an excess return leakage system than for a system with excess leaks at the supply. However, a system with excess supply leaks consumes about $46 \mathrm{kWh}$ on the design day, compared to $43 \mathrm{kWh}$ for excess return leaks or $44 \mathrm{kWh}$ with balanced leaks. This is because the additional house ventilation associated with excess supply leaks also adds load to the house. Excess leakage at the return results in a pressurization of the house and reduces house infiltration. Excess leakage at the supply implies a house depressurization resulting in more infiltration of the hot outside and attic air. In this case, a large amount of energy is therefore used to cool down the hot air resulting from the extra infiltration. This shows that it is not sufficient to only focus on the duct system alone, but the interactions with the house must also be included.

A reduction of the duct surface area reduces the conduction heat transfer and thus reduces the duct losses. The simulation results showed that a decrease of $25 \%$ in the duct surface area results in an increase of around $4 \%$ of the register capacity and the duct efficiency for all climate zones. Reducing the duct area is a simple idea that can be accomplished by placing registers and the air handler near the center of the house. Traditionally, registers are placed around the perimeter of the house to reduce moisture condensation on windows and the discomfort due to radiation 
and drafts from cold windows. With improved window technology in new houses, however, this should no longer be necessary.

Generally, the simulation results show that increasing the duct insulation thickness by about $40 \%$ (R4.2 to R6) increases the register capacity and thus the distribution efficiency by about $4 \%$ (between $3.5 \%$ and $5.5 \%$ depending on the weather conditions. A higher increase from R6 to R8 results in an additional improvement only of $1.9 \%$. Similar results were obtained by Walker (2001) using simplified duct efficiency calculations using the draft ASHRAE Thermal Distribution standard (public review draft of ASHRAE standard 152P (2001)).

\section{Thermostat strategy}

For the one-setpoint thermostat strategy, the good resized system is around $45 \%$ more efficient than the base system. Although it has $25 \%$ less capacity than the base system it provides $14 \%$ more capacity at the registers than the base system and therefore better comfort. The energy consumption for the resized system is around 22 to $28 \%$ lower. As shown in Figure 11, the daily energy consumption is also lower for a pulldown strategy than for a one setpoint situation due to a shorter operating time. This difference ranges from about $10 \%$ (climate zone 8 ) to $25 \%$ (climate zone 15). The tradeoff for saving this energy is a house that gets very hot during the day (around $33^{\circ} \mathrm{C}$ $\left(91^{\circ} \mathrm{F}\right.$ ) for a hot day). This operating strategy may be poor for some households if they have pets, or for food storage.

Using a pulldown thermostat strategy in a hot climate creates uncomfortable conditions for a long time in the house by increasing the time the air conditioner is on before the pulldown is complete. In the simulations, the air conditioner was turned on at 3:00 p.m. and so a criterion for acceptable pulldown comfort is whether the house has completed its pulldown by 5:00 p.m. when the occupants return to the house. This implies a maximum acceptable pulldown time of two hours, or 120 minutes. As shown in Table 7, from climate zone 10 onwards the pulldown time becomes too long and therefore degrades comfort for a base system. For the good resized system this pulldown limit applies only to climates 13 through 15 . This implies the need for the occupants to turn on the air conditioning system earlier or use continuous operation in hotter climates for a base system. This also means that good resized systems are more likely to be operated in the energy saving pulldown mode than base systems. In several cases the time spent above the setpoint is considerable, but in most of these cases the house is close to the setpoint temperature (within about $0.2{ }^{\circ} \mathrm{C}$ ) for most of this time and a small change in setpoint would considerably reduce these times. The exception to this is for the base system in climate zone 15 where the pulldown is so long (more than 5 hours) that it approximate continuous operation and the system cannot control the interior temperature as shown by the large amount of time above the setpoint. 
Climate Zone 8

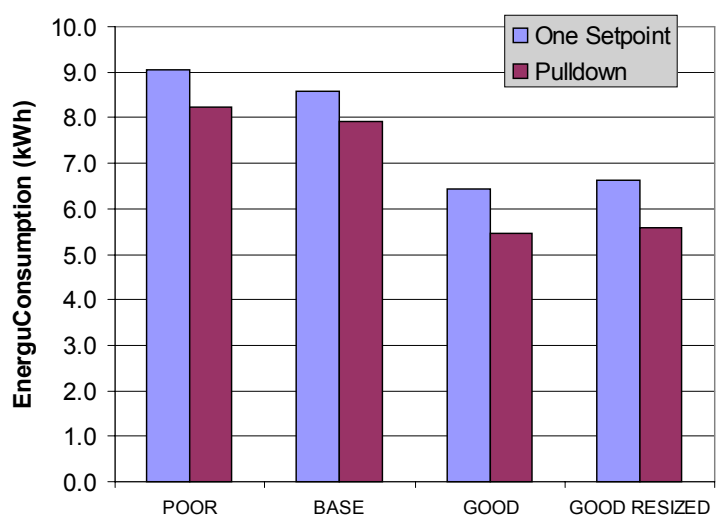

Climate Zone 15

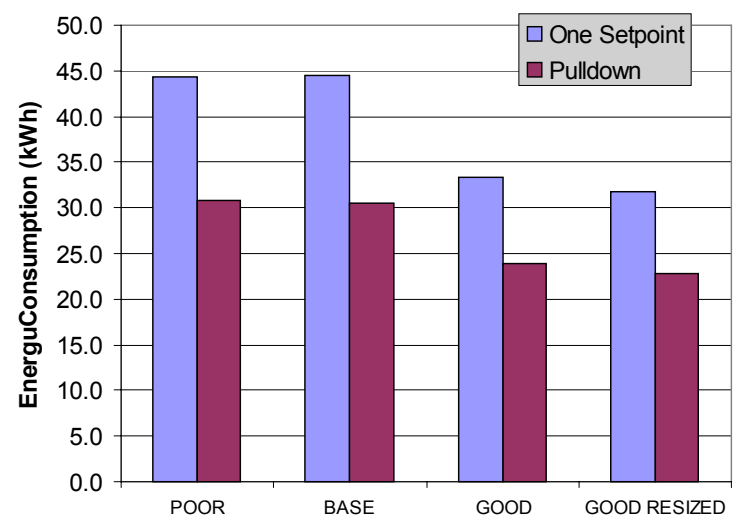

Figure 11: Thermostat Strategy Effects on energy consumption

\begin{tabular}{|c|c|c|c|c|}
\hline \multicolumn{5}{|c|}{$\begin{array}{l}\text { Table7. Number of minutes above the setpoint for the one setpoint thermostat } \\
\text { strategy and pulldown time for the pulldown strategy in each Climate Zone for a } \\
\text { base and a good resized system for a design day }\end{array}$} \\
\hline $\mathrm{CZ}$ & $\begin{array}{c}\text { BASE } \\
\text { 1setpoint strategy }\end{array}$ & $\begin{array}{c}\text { BASE } \\
\text { Pulldown strategy }\end{array}$ & $\begin{array}{l}\text { GOOD Resized } \\
\text { 1setpoint strategy }\end{array}$ & $\begin{array}{l}\text { GOOD Resized } \\
\text { Pulldown strategy }\end{array}$ \\
\hline 8 & 28 & 52 & 33 & 29 \\
\hline 9 & 28 & 19 & 29 & 17 \\
\hline 10 & 24 & 141 & 45 & 115 \\
\hline 11 & 52 & 148 & 63 & 101 \\
\hline 12 & 36 & 131 & 60 & 74 \\
\hline 13 & 38 & 229 & 68 & 191 \\
\hline 14 & 32 & 266 & 64 & 246 \\
\hline 15 & 235 & 318 & 29 & 294 \\
\hline
\end{tabular}

1 setpoint thermostat strategy preferable

A third thermostat strategy was also tested where the system is on the morning between 7 a.m. to 9 a.m. and on the evening from 5 p.m. to 12 p.m. and off the rest of the time. This pre-cooling and operation while it is cooler outside leads to less duct losses and improved equipment performance. In turn, this leads to higher HVAC efficiency during system operation. As shown in Figure 12, this strategy is better than the one setpoint and pulldown strategies. The energy consumption for a base system using this thermostat strategy is between 35 and $80 \%$ less than in the other strategies depending on the climate zone. The drawback for this three setpoint thermostat strategy is that the evening pulldown is not complete until at least 6.30 p.m. For ducts located in the attic, the average register capacity during system operation is between $35 \%$ and $2 \%$ higher than the register capacity of the two other thermostat strategies. This three point strategy shows the most significant improvements when climate zone is hot and the system is poor. When ducts are in the conditioned space, the register capacity and energy consumption of this three setpoint thermostat strategy is about the same as the other thermostat strategies. 


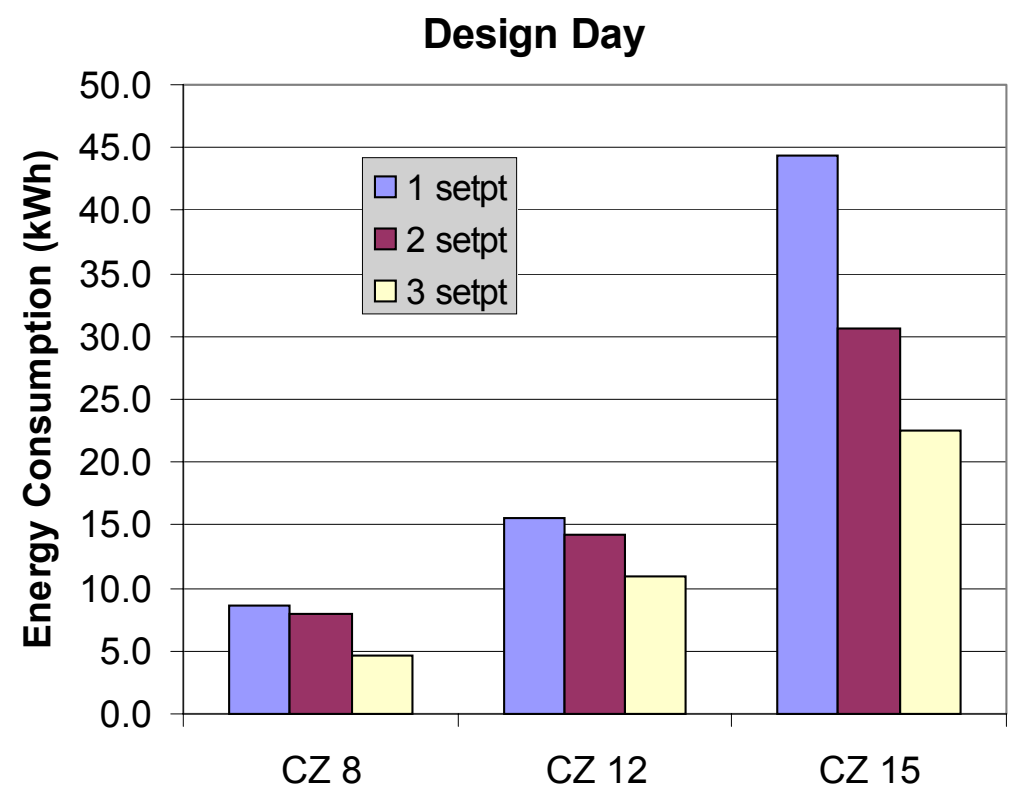

Figure 12. Effects of thermostat strategy on energy consumption

\section{Optimizing good resized system thermostat strategy}

For the pulldown thermostat strategy, the advantages of good resized systems (compared to a base case) such as less energy consumed, a better HVAC efficiency and a lower pulldown time are preserved for all the climate zones studied. However, there are fewer advantages for resizing in the more extreme climate. For example (as shown in Figure 7), the pulldown time for a good resized system is $50 \%$ faster than the base system for climate zone 8 and only $10 \%$ faster in Climate zone 15 .

To investigate if it is possible to optimize the set-up strategy, we varied the time at which the house was to be comfortable (pulldown completed). The simulations were run so as to start the pulldown at different times to complete the pulldown at either 5 p.m. or 6 p.m. Table 6 illustrated the change in system turn-on times between base and good resized systems. Allowing the system to operate later in the day resulted in more energy consumed during the pulldown, but less overall energy for the whole day. This is because the house is conditioned for a smaller fraction of the day (resulting in less total energy consumption), but requires more energy to cool it down (more energy during pulldown). The energy savings for a good resized system are still preserved (greater than 25\%) for the later pulldown. Tables 8 and 9 give details of the energy consumption effects of changing the pulldown time.

Table 8. Energy consumption for climate zone 12, with pulldown ending at 5 p.m.

\begin{tabular}{|c|c|c|c|c|c|c|c|c|}
\hline & \multicolumn{2}{|c|}{ Energy consumed during the pulldown } & \multicolumn{2}{c|}{ Energy consumed during the whole day } \\
\hline Day & \multicolumn{2}{|c|}{ Design day } & \multicolumn{2}{|c|}{ Peak day } & \multicolumn{2}{c|}{ Design day } & \multicolumn{2}{c|}{ Peak day } \\
\hline System & Base & $\begin{array}{c}\text { Good } \\
\text { Resized }\end{array}$ & Base & $\begin{array}{c}\text { Good } \\
\text { Resized }\end{array}$ & Base & $\begin{array}{c}\text { Good } \\
\text { Resized }\end{array}$ & Base & $\begin{array}{c}\text { Good } \\
\text { Resized }\end{array}$ \\
\hline Energy (kWh) & 10.2 & 6.3 & 18.3 & 11.0 & 14.9 & 10.9 & 24.3 & 16.0 \\
\hline $\begin{array}{c}\text { Good Resized } \\
\text { system saving, \% }\end{array}$ & \multicolumn{2}{|c|}{38} & \multicolumn{2}{|c|}{40} & \multicolumn{2}{|c|}{38} \\
\hline
\end{tabular}


Table 9. Energy consumption for climate zone 12, with pulldown ending at 6 p.m.

\begin{tabular}{|c|c|c|c|c|c|c|c|c|}
\hline & \multicolumn{4}{|c|}{ Energy consumed during the pulldown } & \multicolumn{3}{c|}{ Energy consumed during the whole day } \\
\hline Day & \multicolumn{2}{|c|}{ Design day } & \multicolumn{2}{|c|}{ Peak day } & \multicolumn{2}{c|}{ Design day } & \multicolumn{2}{c|}{ Peak day } \\
\hline System & Base & $\begin{array}{c}\text { Good } \\
\text { Resized }\end{array}$ & Base & $\begin{array}{c}\text { Good } \\
\text { Resized }\end{array}$ & Base & $\begin{array}{c}\text { Good } \\
\text { Resized }\end{array}$ & Base & $\begin{array}{c}\text { Good } \\
\text { Resized }\end{array}$ \\
\hline Energy (kWh) & 10.7 & 6.7 & 19.5 & 11.8 & 13.4 & 9.7 & 22.6 & 14.8 \\
\hline $\begin{array}{c}\text { Good Resized } \\
\text { system saving, \% }\end{array}$ & \multicolumn{2}{|c|}{27} & \multicolumn{2}{|c|}{34} & \multicolumn{2}{|c|}{27} & & 34 \\
\hline
\end{tabular}

\section{Effects of moving ducts from the attic to the conditioned space}

To examine the benefits of moving ducts into the conditioned space two more systems were simulated. The indoor base resized and indoor good resized systems have $25 \%$ less capacity than the attic systems. Table 10 shows the single setpoint systems have about $30 \%$ less energy use for indoor systems. The effect of thermostat strategy is illustrated by the pulldown results that show less effect of moving the system inside, with an energy reduction of about $20 \%$.

\begin{tabular}{|c|c|c|c|c|c|c|c|c|}
\hline \multicolumn{9}{|c|}{$\begin{array}{c}\text { Table 10. Energy consumption ( } \mathrm{kWh} \text { ) in each Climate Zone for duct systems inside } \\
\text { conditioned space }\end{array}$} \\
\hline $\begin{array}{l}\text { Climate } \\
\text { Zone }\end{array}$ & $\begin{array}{c}\text { Base } \\
\text { 1 setpoint }\end{array}$ & $\begin{array}{c}\text { Indoor } \\
\text { Base } \\
\text { Resized } \\
\text { 1 setpoint }\end{array}$ & 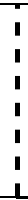 & $\begin{array}{c}\text { Good } \\
\text { Resized } \\
\text { 1 setpoint }\end{array}$ & $\begin{array}{c}\text { Indoor Good } \\
\text { Resized } \\
\text { 1setpoint }\end{array}$ & 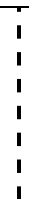 & $\begin{array}{c}\text { Good } \\
\text { Resized } \\
\text { Pulldown }\end{array}$ & $\begin{array}{c}\text { Indoor Good } \\
\text { Resized } \\
\text { Pulldown }\end{array}$ \\
\hline 8 & 8.6 & 5.3 & 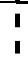 & 6.7 & 4.2 & i & 5.6 & 3.9 \\
\hline 9 & 6.9 & 4.4 & I & 5.3 & 3.3 & i & 4.7 & 3.3 \\
\hline 10 & 17.2 & 11.1 & ! & 12.2 & 8.9 & I & 9.4 & 7.5 \\
\hline 11 & 18.9 & 12.5 & ! & 13.9 & 10.0 & I & 12.2 & 9.4 \\
\hline 12 & 15.6 & 10.6 & ! & 12.5 & 8.6 & 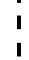 & 10.8 & 8.3 \\
\hline 13 & 27.5 & 17.8 & i & 20.0 & 14.2 & 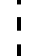 & 16.4 & 12.8 \\
\hline 14 & 33.6 & 23.3 & 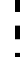 & 24.4 & 18.1 & ! & 18.9 & 14.4 \\
\hline 15 & 44.4 & 31.1 & i & 31.9 & 23.6 & I & 22.8 & 18.9 \\
\hline
\end{tabular}


Table 11. Time above setpoint and pulldown time for a base and a good resized cooling system located either in the attic or in the conditioned space for a design day (minutes)

\begin{tabular}{|c|c|c|c|c|c|c|c|}
\hline & \multicolumn{4}{|c|}{ Time above the setpoint for one setpoint operation } & $\mathbf{I}$ & \multicolumn{2}{|c|}{ Pulldown Time } \\
\hline $\begin{array}{l}\text { Climate } \\
\text { Zone }\end{array}$ & $\begin{array}{c}\text { Base } \\
\text { 1setpoint }\end{array}$ & $\begin{array}{c}\text { Indoor } \\
\text { Base } \\
\text { Resized } \\
\text { 1 setpoint }\end{array}$ & $\begin{array}{c}\text { Good } \\
\text { Resized } \\
\text { 1 setpoint }\end{array}$ & $\begin{array}{c}\text { Indoor Good } \\
\text { Resized } \\
\text { 1setpoint }\end{array}$ & 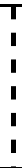 & $\begin{array}{l}\text { Good Resized } \\
\text { Pulldown }\end{array}$ & $\begin{array}{l}\text { Indoor Good } \\
\text { Resized } \\
\text { Pulldown }\end{array}$ \\
\hline 8 & 28 & 18 & 33 & 20 & 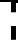 & 29 & 14 \\
\hline 9 & 28 & 18 & 29 & 16 & I & 17 & 11 \\
\hline 10 & 24 & 29 & 45 & 44 & i & 12 & 7 \\
\hline 11 & 34 & 52 & 41 & 42 & i & 10 & 7 \\
\hline 12 & 44 & 36 & 35 & 39 & I & 74 & 18 \\
\hline 13 & 38 & 42 & 68 & 63 & ! & 191 & 89 \\
\hline 14 & 32 & 40 & 64 & 75 & ! & 246 & 172 \\
\hline 15 & 235 & 23 & 29 & 71 & i & 246 & 218 \\
\hline
\end{tabular}

As shown in Table 11, the pulldown time for the indoor good resized systems is between $30 \%$ and $50 \%$ shorter than the pulldown time for the good resized systems. Comfort is therefore improved having ducts in the conditioned space. For single setpoint operation, the time for which the indoor temperature is above the setpoint temperature can be either shorter or longer for indoor ducts depending on the climate zone. This is because of the different system operating times when it is inside or in the attic. As shown in Figure 13A, an attic system has long cycles and the house temperature remains close to $\left(0.1\right.$ or $0.2{ }^{\circ} \mathrm{C}$ under) the setpoint temperature for a considerable time. For the indoor system shown in Figure 13B, there are many shorter cycles, and the house temperature cycles between the lowest and the highest setpoint temperature. This cycling is the reason for the indoor system being above the setpoint for a longer cumulative time over the day than the good resized attic system. In this case, the longer time above the setpoint does not necessarily imply that the interior ducts provide less comfort. Due to reduced duct system losses, the indoor good resized system provides cooler air $\left(13\right.$ to $\left.14^{\circ} \mathrm{C}\right)$ at the register than the good resized system $\left(16\right.$ to $\left.17^{\circ} \mathrm{C}\right)$. This discussion again illustrates how simple analyses for comfort can be misleading without a detailed understanding of system performance.
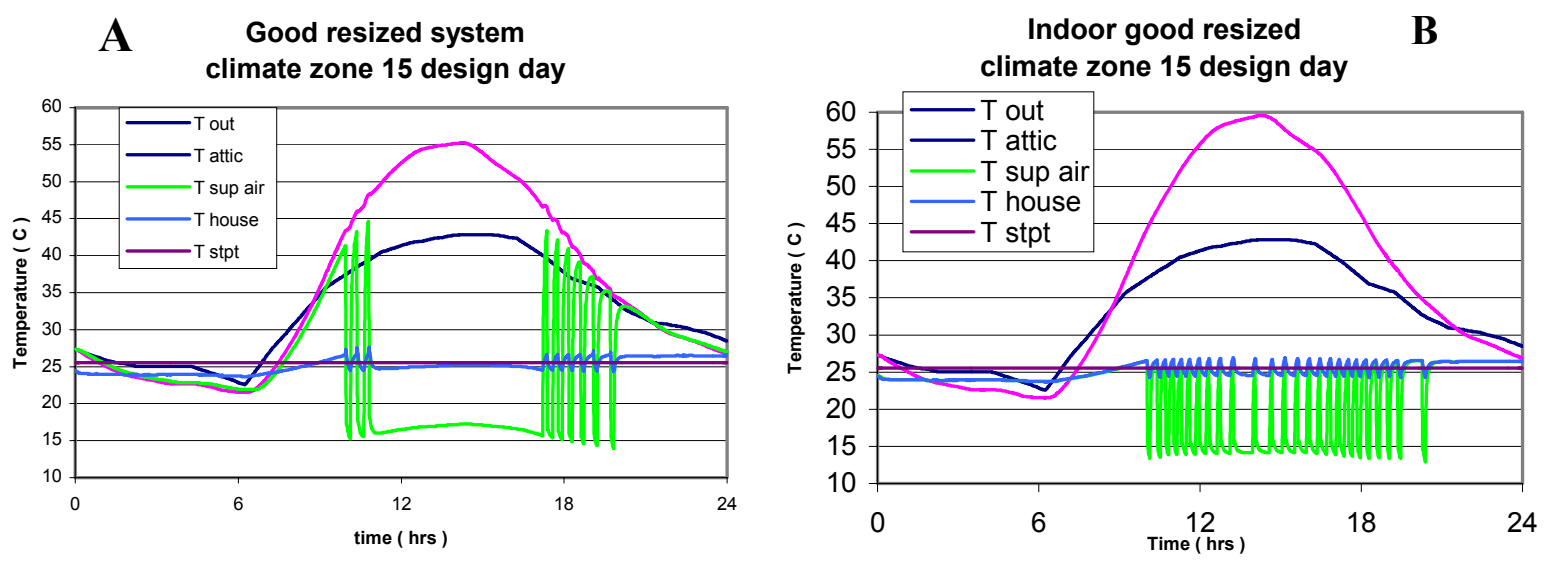

Figure 13. Comparison of cyclic behavior for a good resized system located in the attic or in conditioned space.

\section{Equipment performance}

Comparing the nameplate capacity of the equipment and the TAR (Table 12) shows that the rated capacity is much greater than the effective cooling provided by the HVAC system. The biggest difference is for poor and base systems located in the attic. Their register capacity is less than $40 \%$ of the rated capacity based on the nameplate. This ratio increases to $50 \%$ when these systems are located in the conditioned space. Better systems (good and good 
resized) have their register capacity reaching $60 \%$ of the rated capacity when ducts are located in the attic and $70 \%$ when ducts are inside the house (essentially no losses). The remaining $30 \%$ difference is due to overrating of equipment by manufacturers and not operating the equipment at the ARI rating conditions.

Table 12. Comparison between nameplate capacity and TAR

\begin{tabular}{|c|c|c|c|}
\hline Systems & $\begin{array}{c}\text { TAR } \\
\text { ( Tons ) }\end{array}$ & $\begin{array}{c}\text { Nameplate } \\
\text { capacity } \\
\text { ( Tons ) }\end{array}$ & $\begin{array}{c}\text { Difference } \\
\text { ( \% ) }\end{array}$ \\
\hline Base & 1.6 & 4 & 40 \\
\hline Poor & 1.5 & 4 & 37.5 \\
\hline Good & 2.3 & 4 & 55 \\
\hline Good Resized & 1.7 & 3 & 60 \\
\hline Indoor Base & 1.5 & 3 & 50 \\
\hline Indoor Good Resized & 2.1 & 3 & 70 \\
\hline
\end{tabular}

\section{SIMULATION RESULTS: HEATING}

For the heating systems the simulations did not convert the equipment output energy into energy consumed because there was no explicit model of the heating equipment. For gas furnaces, the efficiency does not change very much unlike air conditioners, so a single furnace efficiency value (such as AFUE) could be used to convert from output energy to energy consumed. Note that the system capacity in these calculations includes the air handler fan power.

For the heating simulation, only two thermostat strategies were tested. The first strategy uses a single setpoint all day. The two setpoint thermostat strategy allows the temperature to drop to $15.5^{\circ} \mathrm{C}\left(60^{\circ} \mathrm{F}\right)$ at night. For the systems simulated here the two setpoint thermostat strategy has about 2 or $3 \%$ better register capacity and between $2.7 \%$ and $5.8 \%$ better HVAC efficiency, depending on the kind of system and the weather. The energy consumption is reduced by about $7 \%$ by using the two setpoint strategy. These results are illustrated in Figure 14. In addition to saving energy, choosing the two setpoint thermostat strategy can be more comfortable for people who prefer lower nighttime temperatures.

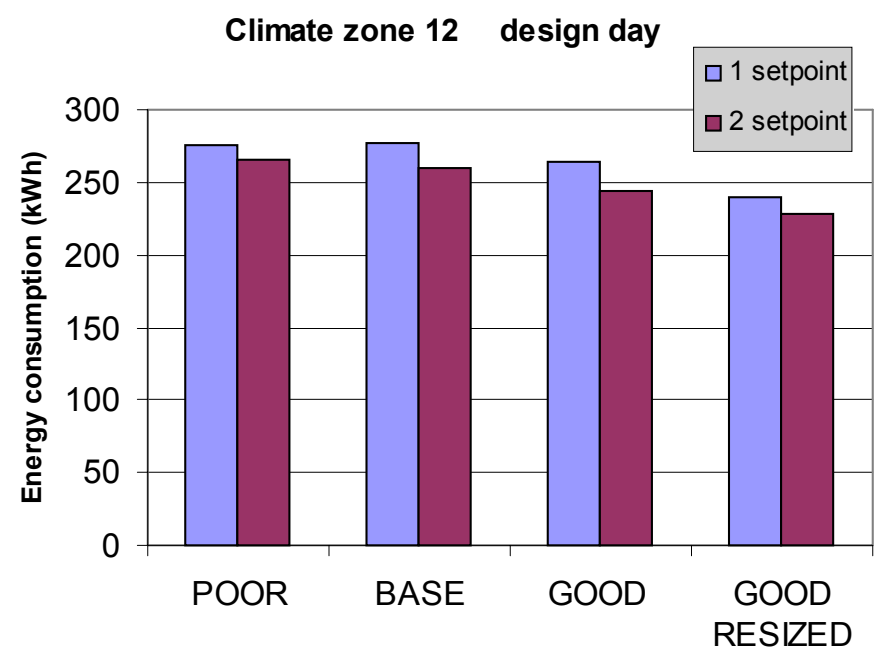

Figure 14. Comparison of thermostat strategies for heating systems

As with the cooling systems, the system efficiency increases as insulation increases. For the heating systems tested here, using R6 insulation instead of R4.2 results in a duct efficiency improvement of $2.5 \%$ to $3 \%$, and the TAR also 
increases by about $1.4 \%$ to $2.8 \%$. Correct air handler flow and less leakage (a good system) have a much bigger effect with a $10 \%$ improvement in register capacity and a $10 \%$ increase in duct efficiency. The air flow and leakage improvements also decrease the energy consumption by $6 \%$ compared to the base system. In addition, the poor systems that are $6 \%$ more leaky than a base system have about $5 \%$ less TAR and duct efficiency in comparison with a base system. However, the poor system total energy consumption for the day is about the same as the base energy consumption due to operating at different times and therefore different attic conditions. In addition to the $25 \%$ power (peak) consumption reduction due to resizing, a good resized system consumes between $10 \%$ and $12 \%$ less energy than a base system for almost all climates, the thermostat strategies and the duct locations.

Two additional heating systems were also tested with the system inside the conditioned space. The example results presented here are for Climate Zone 12, but are typical of other climates also. For heating, the systems in the conditioned space are downsized about $25 \%$ compared to the attic systems. The simulation results show a significant duct efficiency improvement by moving ducts from the attic to the conditioned space. This results in indoor resized systems that deliver $12 \%$ greater TAR than for systems located in the attic. The total energy consumption is reduced between $10 \%$ and $15 \%$ by moving the ducts inside, with a greater effect for base systems than good resized systems.

\section{CONCLUSIONS}

The REGCAP simulation is a good predictor of house and duct system performance, during heating or cooling system operation - which is most important for this study. When the systems are not operating, the simulations do not match the measured data as well, but the errors do not contribute significantly to the energy consumption or system performance parameters.

For all the simulations performed here, a properly sized system (about $25 \%$ capacity reduction) reduces the power consumption and therefore limits peak demand. Even though these correctly sized air conditioning systems have a smaller capacity, they can still provide better or equal comfort than an oversized system by using good duct systems and/or by moving the systems inside conditioned space. The comfort improvement is achieved by supplying a higher register capacity and having a shorter pull down time. For houses operating in pulldown mode (where the house heats up during the day), these correctly sized air-conditioning systems can be turned on later in the day and still achieve the setpoint temperature by the time occupants return to the house in the evening. Generally, the savings and other advantages of a good resized system are greater in more extreme climates. Climate also influences the choice of optimum thermostat strategy - in hot climates only good duct systems should use the pulldown strategy otherwise the house stays too hot for too long. Using good ducts also saves energy - typical improvements over a base case system are in the range of $20 \%-25 \%$, with greater savings in more extreme climates. An investigation of thermostat strategies showed that turning systems off during the day saves energy, but keeping the house conditioned for the whole day may be a good strategy for good resized systems. This is because the energy penalty of continuous conditioning is small for these systems and their pulldown performance is not much faster than for the base case systems. Moving the duct system into conditioned space had significant advantages, even for good systems, and resulted in energy savings of around 30\% for base systems and $15 \%$ for good resized systems.

Similar results were obtained from the heating simulations. Energy and peak demand reductions of about $10 \%$ to $15 \%$ were obtained by good resized systems without sacrificing comfort. An additional 10\% to $15 \%$ savings were realized by moving the duct system inside conditioned space.

For both heating and cooling simulations, the duct improvements tended to be more significant in harsher climates, i.e., those that are hottest in the summer and coldest in the winter. 


\section{REFERENCES}

ACCA. 1986. Manual J - Load Calculations for Residential Winter and Summer Air Conditioning. Washington D.C.; Air Conditioning Contractors of America.

ACCA. 1992. Manual S - Residential Equipment Selection. Washington D.C.: Air Conditioning Contractors of America.

ASHRAE. 2001. Second Public review Draft, ASHRAE Standard 152P. Method of test for determining the Design and Seasonal Efficiencies of Residential Thermal Distribution, ASHRAE, Atlanta, GA.

ASHRAE Fundamentals.1997. Fundamentals, ASHRAE, Atlanta, GA.

ASHRAE Handbook. 1993. Fundamentals, ASHRAE, Atlanta, GA.

Atlas of California. 1979.

Blasnik, M., T. Downey, J. Proctor, and G. Peterson. 1996. Assessment of HVAC Installations in New Homes in APS Service Territory. Proctor Engineering Group Report for Arizona Public Service Company.

Brown, K., C. Blumstein, L. Lutzenhiser, B. Hackett, and Y.J. Huang. 1996. "Does the Air-Conditioning Engineering Rubric Work in Residences?" In Proceedings of the 1996 ACEEE Summer Study on Energy Efficiency in Buildings, 8:11-20. Washington D.C.: American Council for an Energy-Efficient Economy.

Burch, D.M. 1980. Infrared Audits of Roof Heat Loss, ASHRAE Transactions. Vol. 89. ASHRAE, Atlanta, GA.

Burch, D.M. and Luna, D.E. 1980. A Mathematical Model for Predicting Attic Ventilation Rates Required for Prevention of Condensation on Roof Sheathing. ASHRAE Trans. Vol. 86: 201. ASHRAE, Atlanta, GA.

CEC. 1998. Low-rise residential Alternative Calculation Method Approval Manual for 1998 Energy Efficiency Standards for Low-Rise Residential Buildings, California Energy Commission, Sacramento, California.

CEC. 1999. Residential Manual For Compliance with California's 1998 Energy Efficiency Standards. California Energy Commission, Sacramento, California.

ECOTOPE. 1997. Development of a Practical Method for Estimating the Thermal Efficiency of Residential Forced Air Distribution Systems. Electric Power Research Institute Report TR-107744.

Ford, J.K. 1982. Heat Flow and Moisture Dynamics in a Residential Attic. PU/CEES Report \# 148, Princeton University.

Forest, T.W. and Walker, I.S. 1993a. Attic Ventilation and Moisture. Canada Mortgage and Housing Report. March 1993, Ottawa, Canada.

Forest, T.W. and Walker, I.S. 1993b. "Moisture Dynamics in Residential Attics". Proc. CANCAM '93, Queens University, Kingston, Ontario, Canada, June 1993.

Fuji, T. and Imura, H. 1972. Natural Convection Heat Transfer from a plate with Arbitrary Inclination. Int. J. Heat and Mass Trans., Vol. 15, pp. 755-767. NY: Pergamon Press.

Holman, J.P. 1981. Heat transfer- $5^{\text {th }}$ Edition. NY: McGraw-Hill.

Jump, D.A., Walker, I.S. and Modera, M.P. 1996. Field Measurements of Efficiency and Duct Retrofit Effectiveness in Residential Forced air Distribution Systems. Proc. 1996 ACEEE Summer Study, Vol. 1. pp. 147-155. Washington D.C.: American Council for an Energy-Efficient Economy. LBL Report \# 38357.

Mc Adams, W. 1954. Heat Transmission- $3^{\text {rd }}$ Edition, NY: McGraw-Hill. 
Modera, M.P., and Wilcox, B. 1995. Treatment of Residential Duct Leakage in Title-24 Energy Efficiency Standards. CEC contract report. California Energy Commission.

Proctor, J., Z. Katsnelson and B. Wilson. 1995. "Bigger is Not Better: Sizing Air Conditioners Properly." Home Energy, 12(3):19-26.

Proctor, J. and P. Albright. 1996. "Sizing Air Conditioners: If Bigger is not Better, What Is?". Home Energy, 13(5): $13-18$.

Proctor, J. 1997. "Field Measurements of new residential air conditioners in Phoenix, Arizona." ASHRAE Transactions, 103(1): 406-415. ASHRAE, Atlanta, GA.

Proctor, J. 1999. Air Conditioning Equipment Model. Personal Communication, March 1999.

Rodriguez, A.G., O’Neal, D.L., Bain, J.A., and Davis, M.A. 1995. The Effect of Refrigerant Charge, Duct Leakage, and Evaporator Air Flow on the High Temperature Performance of Air Conditioners and Heat Pumps. Energy Systems Laboratory report for EPRI, Texas A\&M University

Siegel, J.A., Walker, I.S., and Sherman, M.H. 2000. Delivering Tons to the Register: Energy Efficient Design and Operation of Residential Cooling Systems. Proceedings of the 2000 ACEEE Summer Study. American Council for an Energy Efficient Economy. (LBNL 45315)

Sharp, G., 2000. "Residential Consumption by End-Use from California Energy Demand 2000”. California Energy Commission. August 23, 2000.

Vieira, R.K., D.S. Parker, J.F Klongerbo., J.K. Stone, J. Cummings. 1996. How Contractors Really Size Air Conditioning Systems. Proceedings of the 1996 ACEEE Summer Study on Energy Efficiency in Buildings, 8:207213. Washington D.C.; American Council for an Energy Efficient Economy.

Wilson, D.J. and Walker, I.S. 1991. Passive Ventilation to Maintain Indoor Air Quality. University of Alberta Department of Mechanical Engineering Report \#81. University of Alberta, Edmonton, Alberta, Canada.

Wilson, D.J., and Walker, I.S. 1992. "Feasibility of Passive Ventilation by Constant Area Vents to Maintain Indoor Air Quality". Proc. Indoor Air Quality '92, ASHRAE/ACGIH/AIHA Conference. San Francisco. October 1992.

Walker, I.S. 1998. Technical Background for Default Values used for Forced Air Systems in Proposed ASHRAE standard 152P. ASHRAE Trans. Vol.104 Part 1. (LBNL 40588).

Walker, I.S., J. Siegel, K. Brown, M.H. Sherman. 1998. Saving Tons at the Register. Proceedings of the 1998 ACEEE Summer Study on Energy Efficiency in Buildings, 1:367-385. Washington D.C.: American Council for an Energy-Efficient Economy. (LBNL 41957).

Walker, I.S, Sherman, M, Siegel, J. 1999. Distribution Effectiveness and Impacts on Equipment Sizing for Residential Thermal Distribution Systems.LBNL-43724.

Walker, I.S., 2001. Sensitivity of Forced Air Distribution System Efficiency to Climate, Duct Location, Air Leakage and Insulation. LBNL 43371.

Walker, I.S., Siegel, J.A., Degenetais, G. 2001. Simulation of Residential HVAC System Performance. Proc. ESIM2001 Conference, CANMET Energy Technology Centre/Natural Resources Canada, Ottawa, Canada. pp. 4350. LBNL 47622. 


\section{Appendix 1. SIMPLIFYING ASSUMPTIONS FOR REGCAP}

In order to simplify the calculation procedure, several key assumptions are made. These simplifications strike a balance between complexity and what can be reasonably known about the building. The assumptions discussed here will focus on the heat transfer part of REGCAP because this is where the cooling and heating system effects are most important. The basis of the thermal model in REGCAP is that a set of sixteen nodes is defined throughout the house and HVAC system, and a set of equations is solved to find the temperature at each node. The 16 nodes are shown in Figure 1. The heat fluxes into each node are calculated and then a finite difference approximation is used to find the change in temperature of the node:

$$
\rho \mathrm{VC}_{\mathrm{p}}\left(\mathrm{T}-\mathrm{T}_{\text {previous }}\right) / \tau=\Sigma \mathrm{Q}
$$

Where: $\rho=$ density of node material $\left(\mathrm{kg} / \mathrm{m}^{3}\right)$

$\mathrm{V}=$ volume of node $\left(\mathrm{m}^{3}\right)$

$\mathrm{C}_{\mathrm{p}}=$ specific heat of node material $(\mathrm{J} / \mathrm{KgK})$

$\mathrm{T}=$ current temperature of the node $\left({ }^{\circ} \mathrm{C}\right.$ or $\left.\mathrm{K}\right)$

$\mathrm{T}_{\text {previous }}=$ previous temperature of node $\left({ }^{\circ} \mathrm{C}\right.$ or $\left.\mathrm{K}\right)$

$\tau=$ Time step. For the simulations in this study this is set to one minute $(60 \mathrm{~s})$.

$\mathrm{Q}=$ heat flux into node $(\mathrm{W})$

The specific heat of the building materials and the air are assumed to be constant (rather than a function of temperature) because the difference is insignificant: $0.002 \mathrm{~J} / \mathrm{kgK}$ variation over the temperature range used in this study.

The heat flux is composed of:

$$
\begin{aligned}
& \text { Conduction: } \quad \mathrm{Q}=\mathrm{A} \Delta \mathrm{T} / \mathrm{R} \quad \text { with } \quad \mathrm{R}=\text { Thermal Resistance between nodes }\left(\mathrm{m}^{2} \mathrm{~K} / \mathrm{W}\right) \\
& \mathrm{A}=\text { Surface Area over which heat transfer occurs }\left(\mathrm{m}^{2}\right) \\
& \Delta \mathrm{T}=\text { Temperature difference between nodes }\left({ }^{\circ} \mathrm{C} \text { or } \mathrm{K}\right)
\end{aligned}
$$

Convection: $\quad \mathrm{Q}=\mathrm{h}_{\mathrm{c}} \mathrm{A} \Delta \mathrm{T}$ with $\mathrm{h}_{\mathrm{c}}=$ convection heat transfer coefficient $\left(\mathrm{W} / \mathrm{m}^{2} \mathrm{~K}\right)$

Radiation: $\quad \mathrm{Q}=\mathrm{h}_{\mathrm{r}} \mathrm{A} \Delta \mathrm{T}$ with $\mathrm{h}_{\mathrm{r}}=$ radiation heat transfer coefficient $\left(\mathrm{W} / \mathrm{m}^{2} \mathrm{~K}\right)$, and $\mathrm{h}_{\mathrm{r}}$ is a function of the surface temperature to the third power $\left(\mathrm{T}^{3}\right)$. To linearize this radiation heat transfer, $\mathrm{h}_{\mathrm{r}}$ is determined using temperatures from the previous time step. Because the time steps used in this study are so short (one minute) the linearization errors are insignificant.

For the air nodes $(1,12,15$ and 16), the energy in the airflows in and out of the nodes are also included in the energy balance.

The finite difference approximation used in Equation A1.1 implies that the temperature distribution is uniform for each node. For solid nodes, this assumption is tested by the calculation of the non-dimensional Biot number (Bi):

$$
\begin{aligned}
& \mathrm{Bi}=\mathrm{h}_{\mathrm{c}} \mathrm{L} / \mathrm{k} \quad \text { with } \quad \mathrm{h}_{\mathrm{c}}=\text { exterior convention heat transfer coefficient }\left(\mathrm{W} / \mathrm{m}^{2} \mathrm{~K}\right) \\
& \mathrm{L}=\text { characteristic length }(\mathrm{m}) \text {. Usually determined by } \mathrm{V} / \mathrm{A} \text {, the volume to } \\
& \text { surface area ratio for the node. } \\
& \mathrm{k}=\text { thermal conductivity }(\mathrm{Km} / \mathrm{W})
\end{aligned}
$$

For most the solid nodes, it was found that $\mathrm{Bi}<0.1$. Therefore, the constant temperature assumption is acceptable. The key exception is for the house thermal mass if the foundation is slab on grade. To keep the model simple a single node was used for the house thermal mass, but in the future it is possible that a multi-node approach may be used. The effective thermal mass of the house and attic wood were determined by using assumptions about known construction techniques and scaling the mass with the size of the house.

Most of the surfaces in the attic undergo both natural and forced convection. In REGCAP, the relationship for forced convection is based on empirical relationships from Burch (1980) and McAdams (1954). For forced convection due to ventilation or handler driven air flows, the forced convection coefficient is determined by using the Nusselt relation: 


$$
\mathrm{Nu}=\mathrm{h}_{\text {forced }} \mathrm{L} / \mathrm{k}=0.037 \mathrm{Re}^{4 / 5} \operatorname{Pr}^{1 / 3}
$$

Where: Reynolds Number: $\mathrm{Re}=\mathrm{uL} / \mathrm{v}$

Prandlt Number: $\operatorname{Pr}=v / \lambda$

where $\lambda$ is the thermal diffusion coefficient $\left(\mathrm{m}^{2} / \mathrm{s}\right)$

$v$ the viscosity $\left(\mathrm{s} / \mathrm{m}^{2}\right)$

$\mathrm{u}$ the air velocity $(\mathrm{m} / \mathrm{s})$.

This equation can be linearized over the range of temperatures commonly seen in building simulations (between $250 \mathrm{~K}$ and $300 \mathrm{~K})$ :

$$
\mathrm{h}_{\text {forced }}=\left(6.940-0.0344 \mathrm{~T}_{\text {film }}\right) \mathrm{u}^{4 / 5} \mathrm{~L}^{-1 / 5}
$$

$\mathrm{T}_{\text {film }}$ is the average of the air and surface temperature and $\mathrm{L}$ (the characteristic length) is assumed to be $0.5 \mathrm{~m}$ for an attic.

For natural convection in the attic and house a single orientation is chosen for simplicity, such that the Nusselt number $(\mathrm{Nu})$ is given by the following relationship (from Fuji and Imura 1972):

$$
\mathrm{Nu}=0.13(\mathrm{Gr} \operatorname{Pr})^{1 / 3}
$$

Where: $\mathrm{Gr}=\frac{g \beta \Delta T L^{3}}{v^{2}}$

$\operatorname{Pr}=\frac{v}{\lambda}$, and $\beta=$ Volume coefficient thermal expansion, and $g=\operatorname{gravitational}$ acceleration $\left(\mathrm{m} / \mathrm{s}^{2}\right)$

For air: $\operatorname{Pr}=0.71, \mathrm{k}=0.02624 \mathrm{~W} / \mathrm{mK}$, and $\mathrm{Gr}=2084 \mathrm{~L}^{3} \Delta \mathrm{T}$, therefore, the natural convection heat transfer coefficient is given by:

$$
\mathrm{h}_{\mathrm{T}}=3.2(\Delta \mathrm{T})^{1 / 3}
$$

The overall convection is determined combining the forced and natural coefficients in the following empirical equation that allows the dominant heat transfer effect to dominate the overall heat transfer coefficient:

$$
\mathrm{h}_{\text {total }}=\sqrt[3]{h_{\text {natural }}^{3}+h_{\text {forced }}^{3}}
$$

Equation A1.6 is not applied to nodes 7 and 13, the underside of the ceiling and the house mass, respectively. For these, $\mathrm{h}_{\text {total }}$ is set equal to $6 \mathrm{~W} / \mathrm{m}^{2} \mathrm{~K}$ when the air handler is off and $9 \mathrm{~W} / \mathrm{m}^{2} \mathrm{~K}$ when the air handler is on. This is based on equations developed empirically in ASHRAE Fundamentals (Fundamentals 1997) (chapter 3) for determining heat transfer on interior surfaces:

$$
\mathrm{h}_{\text {total }}=5.62+3.9 \mathrm{u}=7 \mathrm{~W} / \mathrm{m}^{2} \mathrm{~K}
$$

The small range of this heat transfer coefficient over the expected range of interior velocities shows that the assumption is not critical:

For $\mathrm{u}=0.1 \mathrm{~m} / \mathrm{s} \quad \mathrm{h}=6 \mathrm{~W} / \mathrm{m}^{2} \mathrm{~K}$ (low velocity)

For $\mathrm{u}=0.3 \mathrm{~m} / \mathrm{s} \quad \mathrm{h}=7 \mathrm{~W} / \mathrm{m}^{2} \mathrm{~K}$ (typical velocity when the air handler is off)

For $\mathrm{u}=1 \mathrm{~m} / \mathrm{s} \quad \mathrm{h}=9.5 \mathrm{~W} / \mathrm{m}^{2} \mathrm{~K}$ (extreme velocity)

Internal radiation heat transfer is only calculated for the attic surfaces (nodes $2,4,8,11$, and 14) because only the attic has temperature differences high enough to cause significant radiant exchange from the point of view of thermal loads on house and ducts. The wood in the roof trusses may contribute to radiation exchange but the geometry is too complex and the net effect too small to model. The ducts are also included in the radiation exchange in the attic. The ducts are assumed to have the upper half of their surface area exchanging radiation with the sheathing, and one half not active in radiant heat transfer because it lies on the floor of the attic. This "half active" approach was determined semi-empirically by performing detailed comparisons of measured to modeled data as well as observing duct installations in houses. 
Initial temperatures need to be assumed for all the temperature nodes at the beginning of the simulation. The initial attic, supply, return temperatures are fixed equal to the initial outdoor temperature. The initial house temperature is equal to the thermostat setpoint temperature minus one $\mathrm{K}$, and the initial house mass temperature is the setpoint minus two K. Our simulation results have shown that these initial temperature assumptions are not critical, because they only have an effect for about the first 30 minutes of any simulation. The exception is the initial house thermal mass temperature that can be critical in some simulations. The simple model for initial house mass temperature used here was based on many empirical comparisons of measured and simulated temperatures in California houses.

For the air nodes it is assumed that the air is well mixed and therefore of uniform temperature. This assumption is reasonable for ducts because they have a small volume and large airflows during system operation. For the house air, the air handler mixes the air during system operation. With the air handler off, the house may become stratified or have room-to-room temperature differences (e.g., because of different solar loads), but this has a small effect on building load and even less effect on duct system performance. Because there is no active mixing of attic air it can have significant thermal stratification. Determining the attic thermal stratification is an extremely complex problem because it requires detailed knowledge of all the air flows through individual attic leaks and the interactions between the complex internal geometry of attic surfaces all at potentially different temperatures. Because this stratification could not be accurately modeled it is not included in the REGCAP model. This attic stratification could have a significant effect on duct system performance if the air around the ducts was at a different temperature than the rest of the attic air. The comparisons that have been made to measured data would then show a bias in the calculated duct system performance. Because verification comparisons did not show this bias it can be assumed that the attic stratification does not have a significant effect.

For air flows, the house and attic are both treated as single zones. Most attic spaces are of open construction and a single zone is a good assumption. Houses tend to be compartmentalized by interior partitions and if doors are closed between rooms the house will have several linked interior zones. If this study focused on predicting heat and air movement for individual rooms, then this would be a concern, but when determining overall values for the whole house the single zone approach is adequate. In addition, the extra information on the flow resistance of all the flow pathways between all the rooms of the house is almost impossible to determine, and therefore the required input information for a more complex model is generally unknown. One significant aspect of the single zone assumption is that it ignores heat transfer through the ducts with the air handler off that is transported by air flow through the ducts from room to room. This is generally not a problem for this study because this is such a small part of the load for the whole house. Some simple calculations show that the room-to-room flows through attic ducts contribute less than $100 \mathrm{~W}$ to the house load. However, REGCAP does include air flows (and the associated heat transfer) between the house and the attic through the duct leaks when the air handler system is off.

The geometry of the house is assumed to have a square floor plan that influences the wall surface area (for estimating house conduction load) and wind pressure coefficients (for estimating ventilation driving pressures). For more complex house shapes the wall surface area will be proportionally larger (for the same floor area). Because the house load is modeled so simply, the added complication of explicitly specify a complex house shape was not justifiable. Also, for comparing the performance of different systems in this study, the simple house shape is the same in all cases. Similarly, the pressure coefficient data is unknown for specific complex building shapes and the infiltration rate is not strongly affected by specific geometry unless there are very specific known leaks. 
Appendix 2: CALIFORNIA Climate ZONES

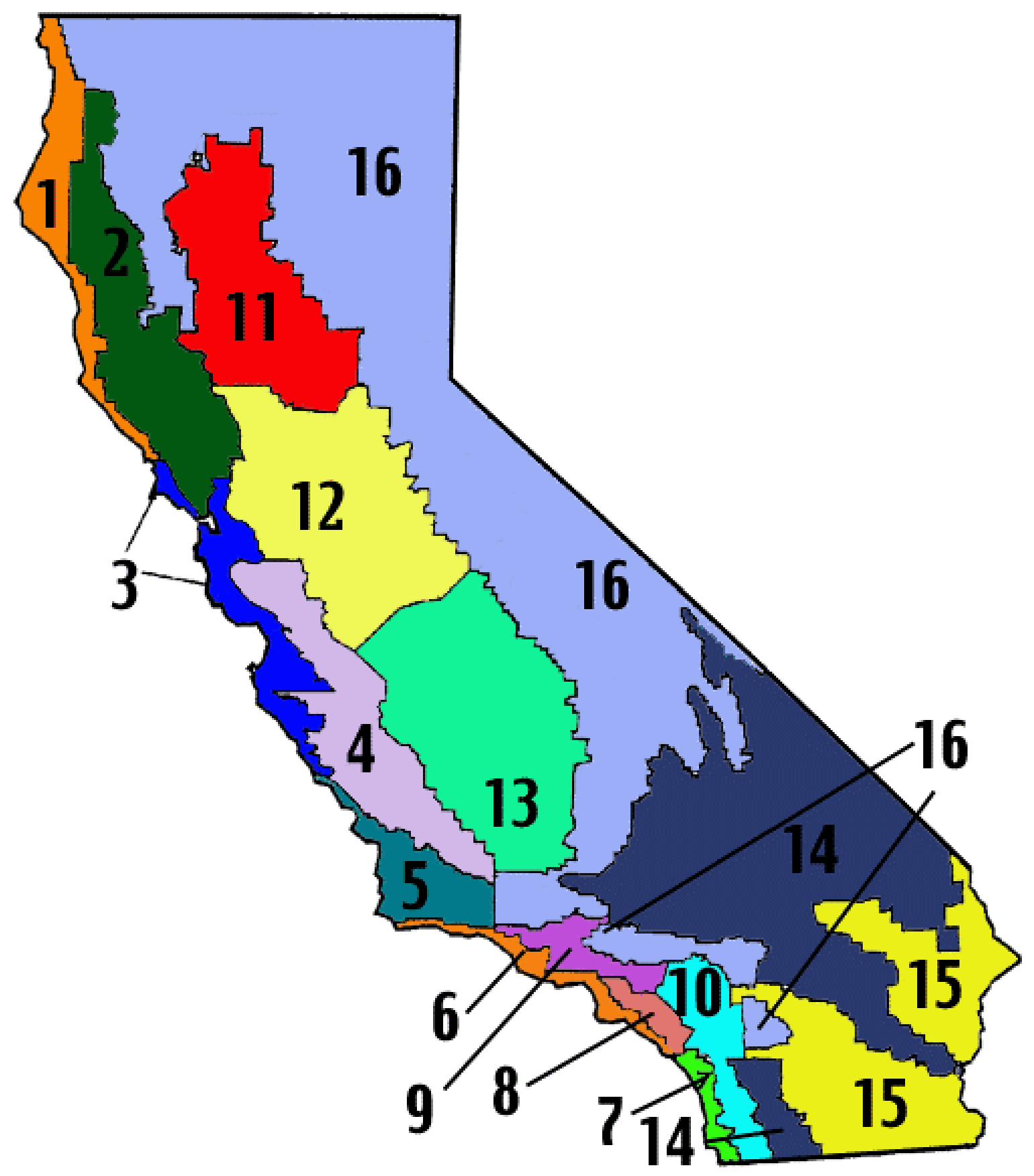


Appendix 3: MEAN ALTITUDE AND LATITUDE OF EACH CLIMATE ZONE

\begin{tabular}{|c|c|c|c|c|c|c|c|c|}
\hline $\begin{array}{c}\text { Climate } \\
\text { Zone }\end{array}$ & $\mathbf{1}$ & $\mathbf{2}$ & $\mathbf{3}$ & $\mathbf{4}$ & $\mathbf{5}$ & $\mathbf{6}$ & $\mathbf{7}$ & $\mathbf{8}$ \\
\hline $\begin{array}{c}\text { Latitude } \\
\text { (degres) }\end{array}$ & 41 & 40 & 38 & 36 & 34.5 & 34 & 33 & 34 \\
\hline $\begin{array}{c}\text { Altitude } \\
(m)\end{array}$ & 350 & 1000 & 300 & 500 & 200 & 150 & 100 & 200 \\
\hline
\end{tabular}

\begin{tabular}{|c|c|c|c|c|c|c|c|c|}
\hline $\begin{array}{c}\text { Climate } \\
\text { Zone }\end{array}$ & $\mathbf{9}$ & $\mathbf{1 0}$ & $\mathbf{1 1}$ & $\mathbf{1 2}$ & $\mathbf{1 3}$ & $\mathbf{1 4}$ & $\mathbf{1 5}$ & $\mathbf{1 6}$ \\
\hline $\begin{array}{c}\text { Latitude } \\
\text { (degres) }\end{array}$ & 34.5 & 33 & 40 & 38 & 35 & 35 & 34 & 39 \\
\hline $\begin{array}{c}\text { Altitude } \\
(m)\end{array}$ & 250 & 1100 & 200 & 200 & 200 & 1000 & 600 & 1800 \\
\hline
\end{tabular}

Sources: $\quad$ Altitude: Atlas of California p 115

Latitude: Map in Internet http://fermi.jhuapl.edu/states/maps 1/ca.gif 


\section{Appendix 5: PEAK AND DESIGN WEATHER DATA FOR EACH CLIMATE ZONE}

These data were determined by using the CEC, T24 hourly weather data for each climate zone. They were sorted by the outside temperature. Then it was easy to find out the peak temperature corresponding either to the coolest or the hottest temperature depending on the studied situation. The design temperature were found by looking at the most usual temperature around the day 35 ( $1 \%$ of the number of days).

\begin{tabular}{|c|c|c|c|c|c|c|c|c|c|}
\hline & $\mathrm{CZ}$ & 1 & 2 & 3 & 4 & 5 & 6 & 7 & 8 \\
\hline \multirow[t]{4}{*}{ COOL } & Peak Day & $\begin{array}{c}274 \\
10 / 01 \\
\end{array}$ & $\begin{array}{c}232 \\
08 / 21 \\
\end{array}$ & $\begin{array}{c}271 \\
09 / 28 \\
\end{array}$ & $\begin{array}{c}199 \\
07 / 18 \\
\end{array}$ & $\begin{array}{c}247 \\
09 / 04 \\
\end{array}$ & $\begin{array}{c}267 \\
09 / 24 \\
\end{array}$ & $\begin{array}{c}254 \\
09 / 11 \\
\end{array}$ & $\begin{array}{c}267 \\
09 / 24 \\
\end{array}$ \\
\hline & $\operatorname{Peak} T\left({ }^{\circ} \mathrm{C}\right)$ & 26.5 & 37.2 & 32.7 & 36.3 & 33.8 & 31.7 & 33.3 & 36.6 \\
\hline & Design Day & $\begin{array}{c}173 \\
06 / 22 \\
\end{array}$ & $\begin{array}{c}166 \\
06 / 15 \\
\end{array}$ & $\begin{array}{c}117 \\
04 / 27 \\
\end{array}$ & $\begin{array}{c}185 \\
07 / 04 \\
\end{array}$ & $\begin{array}{c}93 \\
04 / 03 \\
\end{array}$ & $\begin{array}{c}172 \\
06 / 21 \\
\end{array}$ & $\begin{array}{c}253 \\
09 / 10 \\
\end{array}$ & $\begin{array}{c}252 \\
09 / 09 \\
\end{array}$ \\
\hline & Design $T\left({ }^{\circ} \mathrm{C}\right)$ & 21.9 & 33.7 & 26.6 & 30 & 26.9 & 25.8 & 28 & 31.8 \\
\hline \multirow[t]{4}{*}{ HEAT } & Peak Day & $\begin{array}{c}356 \\
12 / 22 \\
\end{array}$ & $\begin{array}{c}12 \\
01 / 12\end{array}$ & $\begin{array}{c}362 \\
12 / 28 \\
\end{array}$ & $\begin{array}{c}355 \\
12 / 21 \\
\end{array}$ & $\begin{array}{c}360 \\
12 / 26 \\
\end{array}$ & $\begin{array}{c}363 \\
12 / 29 \\
\end{array}$ & $\begin{array}{c}6 \\
01 / 06\end{array}$ & $\begin{array}{c}346 \\
12 / 12 \\
\end{array}$ \\
\hline & Peak T $\left({ }^{\circ} \mathrm{C}\right)$ & -0.2 & -2.4 & 1.2 & -2 & -0.8 & 3.5 & 2.7 & 1.3 \\
\hline & Design Day & $\begin{array}{c}313 \\
11 / 09\end{array}$ & $\begin{array}{c}338 \\
12 / 04\end{array}$ & $\begin{array}{c}353 \\
12 / 19 \\
\end{array}$ & $\begin{array}{c}350 \\
12 / 16\end{array}$ & $\begin{array}{c}16 \\
01 / 16\end{array}$ & $\begin{array}{c}360 \\
12 / 26 \\
\end{array}$ & $\begin{array}{c}7 \\
01 / 07 \\
\end{array}$ & $\begin{array}{c}8 \\
01 / 08 \\
\end{array}$ \\
\hline & Design $T\left({ }^{\circ} \mathrm{C}\right)$ & 2.8 & -0.1 & 4.1 & 1.7 & 2.4 & 6.6 & 6 & 4.6 \\
\hline
\end{tabular}

\begin{tabular}{|c|c|c|c|c|c|c|c|c|c|}
\hline & $\mathbf{C Z}$ & 9 & 10 & 11 & 12 & 13 & 14 & 15 & 16 \\
\hline \multirow[t]{4}{*}{$\overline{\mathrm{COOL}}$} & Peak Day & $\begin{array}{c}267 \\
09 / 24\end{array}$ & $\begin{array}{c}225 \\
08 / 14\end{array}$ & $\begin{array}{c}196 \\
09 / 15 \\
\end{array}$ & $\begin{array}{c}205 \\
07 / 24\end{array}$ & $\begin{array}{c}208 \\
07 / 27\end{array}$ & $\begin{array}{c}192 \\
07 / 11\end{array}$ & $\begin{array}{c}188 \\
07 / 17 \\
\end{array}$ & $\begin{array}{c}218 \\
08 / 07 \\
\end{array}$ \\
\hline & Peak T $\left({ }^{\circ} \mathrm{C}\right)$ & 38.9 & 40.1 & 40.4 & 39.7 & 41.3 & 41.2 & 46.3 & 35.5 \\
\hline & Design Day & $\begin{array}{c}153 \\
09 / 10\end{array}$ & $\begin{array}{c}246 \\
09 / 03\end{array}$ & $\begin{array}{c}221 \\
08 / 10 \\
\end{array}$ & $\begin{array}{c}209 \\
07 / 28 \\
\end{array}$ & $\begin{array}{c}216 \\
08 / 07\end{array}$ & $\begin{array}{c}177 \\
06 / 26 \\
\end{array}$ & $\begin{array}{c}256 \\
09 / 03 \\
\end{array}$ & $\begin{array}{c}222 \\
08 / 11 \\
\end{array}$ \\
\hline & Design $T\left({ }^{\circ} \mathrm{C}\right)$ & 34.3 & 35.7 & 36.5 & 35.5 & 37 & 37.8 & 43 & 31.4 \\
\hline \multirow[t]{4}{*}{$\overline{\text { HEAT }}$} & Peak Day & $\begin{array}{c}347 \\
12 / 13\end{array}$ & $\begin{array}{c}346 \\
12 / 12\end{array}$ & $\begin{array}{c}5 \\
01 / 05\end{array}$ & $\begin{array}{c}358 \\
12 / 24\end{array}$ & $\begin{array}{c}355 \\
12 / 21\end{array}$ & $\begin{array}{c}359 \\
12 / 25\end{array}$ & $\begin{array}{c}363 \\
12 / 29\end{array}$ & $\begin{array}{c}354 \\
12 / 20\end{array}$ \\
\hline & Peak T $\left({ }^{\circ} \mathrm{C}\right)$ & 0.9 & -0.5 & -2.8 & -2.9 & -1.9 & -8 & 0.1 & -11.2 \\
\hline & Design Day & $\begin{array}{c}325 \\
11 / 21\end{array}$ & $\begin{array}{c}320 \\
11 / 16 \\
\end{array}$ & $\begin{array}{c}349 \\
12 / 15 \\
\end{array}$ & $\begin{array}{c}357 \\
12 / 23 \\
\end{array}$ & $\begin{array}{c}338 \\
12 / 04 \\
\end{array}$ & $\begin{array}{c}8 \\
01 / 08 \\
\end{array}$ & $\begin{array}{c}362 \\
12 / 28 \\
\end{array}$ & $\begin{array}{c}343 \\
12 / 09 \\
\end{array}$ \\
\hline & Design $T\left({ }^{\circ} \mathrm{C}\right)$ & 5.1 & 2.6 & 0.5 & 0.9 & 1.7 & -3.1 & 3.9 & -6.1 \\
\hline
\end{tabular}




\section{Appendix 6: PLAN AND DIMENSIONS OF THE HOUSE}

\section{First Floor}

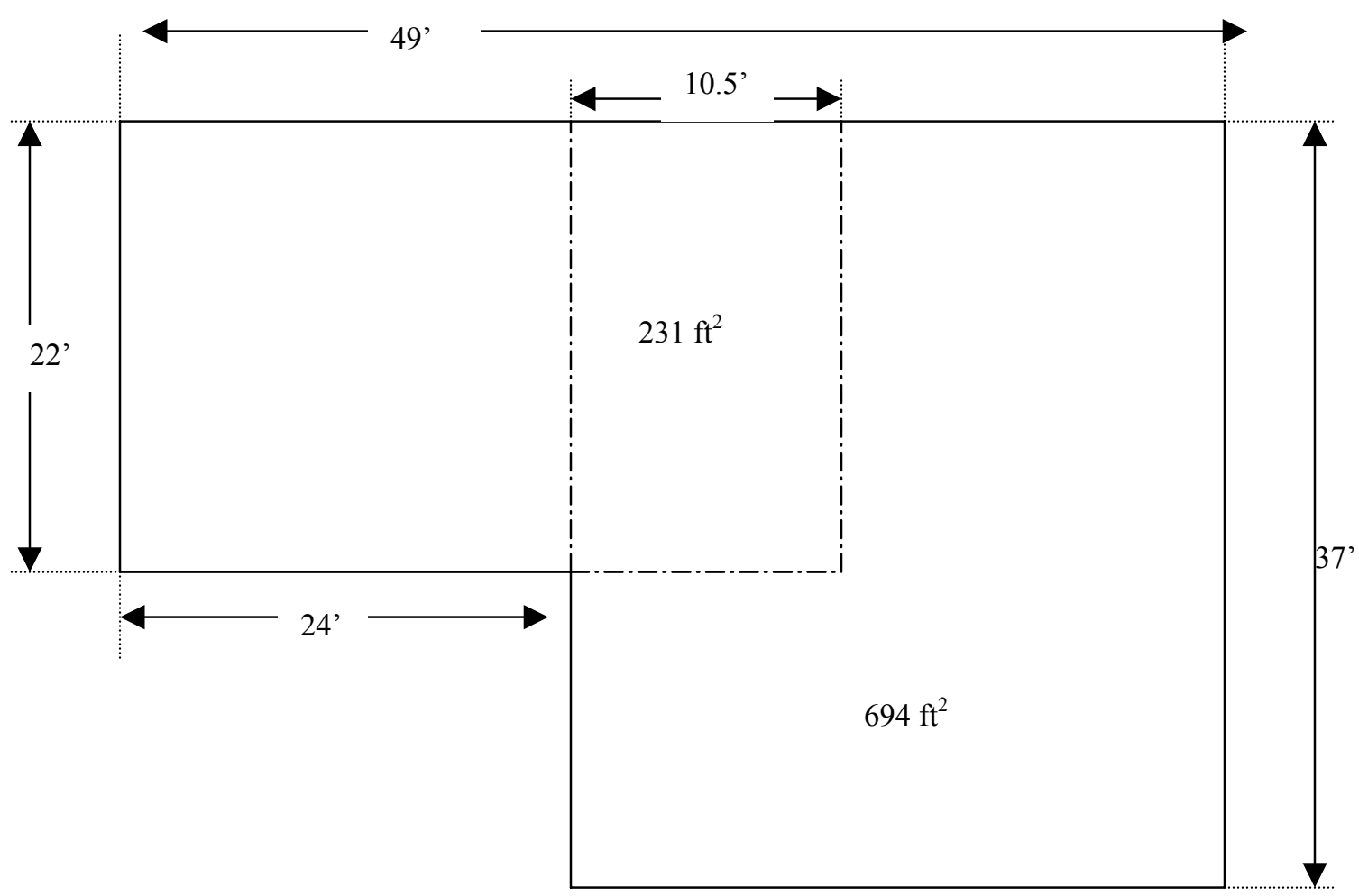

Second Floor

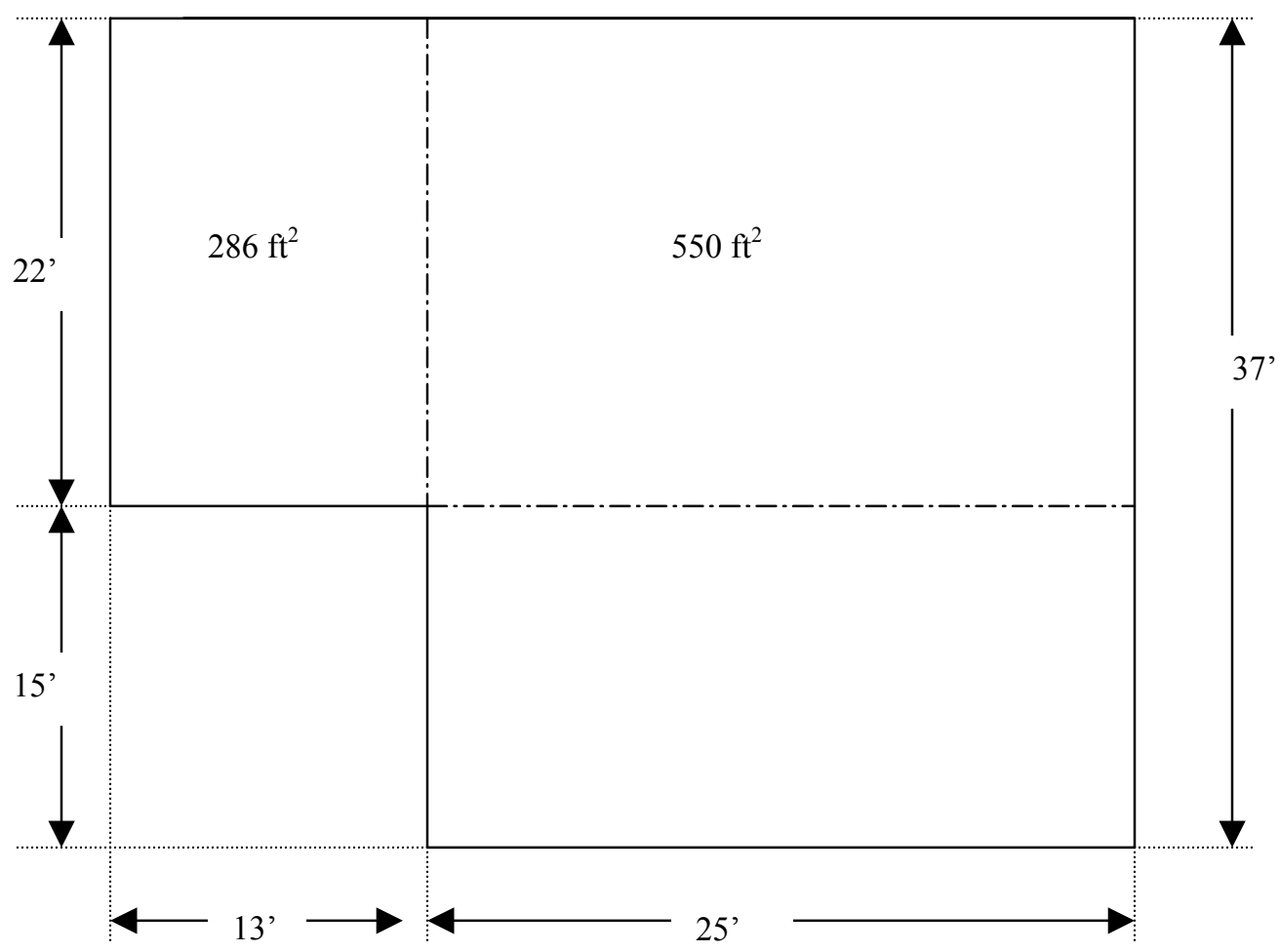


West Elevation
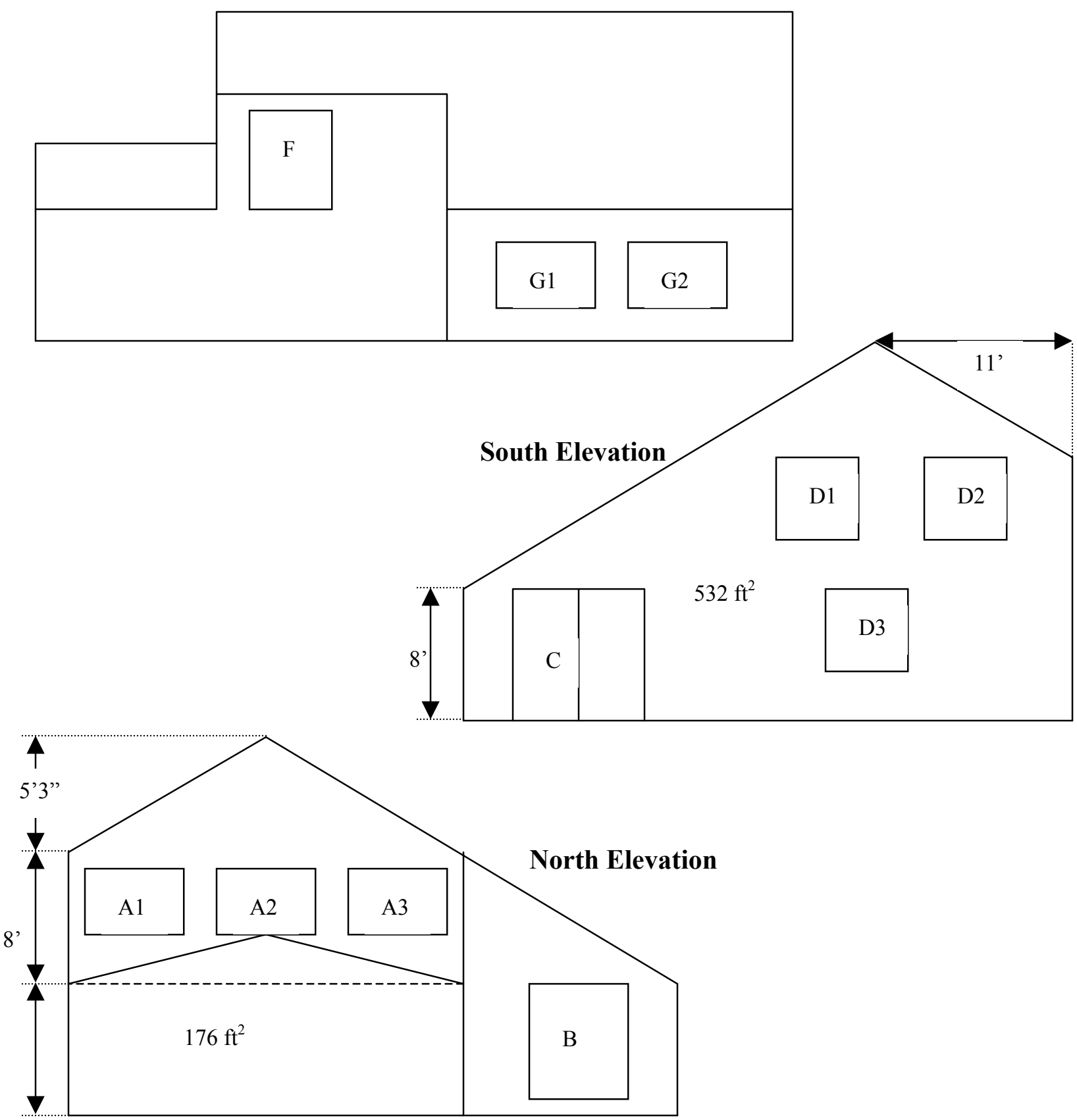

East Elevation

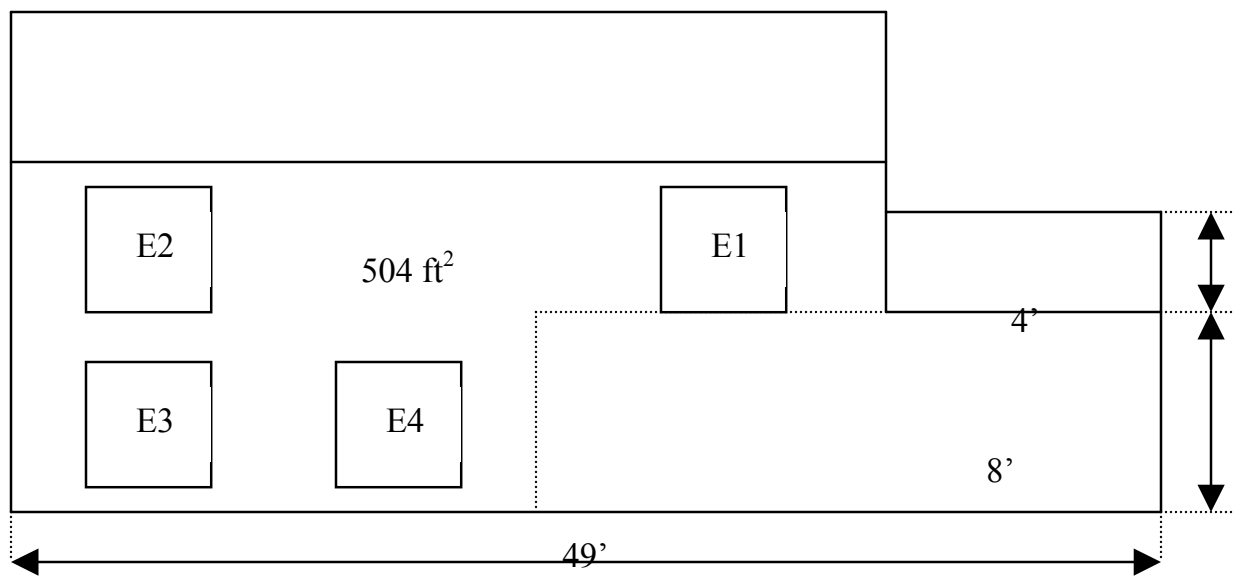




\begin{tabular}{|c|c|c|c|}
\hline $\begin{array}{l}\text { PERIMETER (ft) } \\
\text { Exposed (uncond) } \\
\text { Covered (outside) } \\
\text { Exposed (outside) }\end{array}$ & $\begin{array}{c}22 \\
91.5 \\
10.5\end{array}$ & $\begin{array}{l}\text { VOLUME }\left(\mathrm{ft}^{3}\right) \\
\text { Total } \\
1^{\text {st }} \text { floor } \\
2^{\text {nd }} \text { floor }\end{array}$ & $\begin{array}{c}15588 \\
8900 \\
6688\end{array}$ \\
\hline 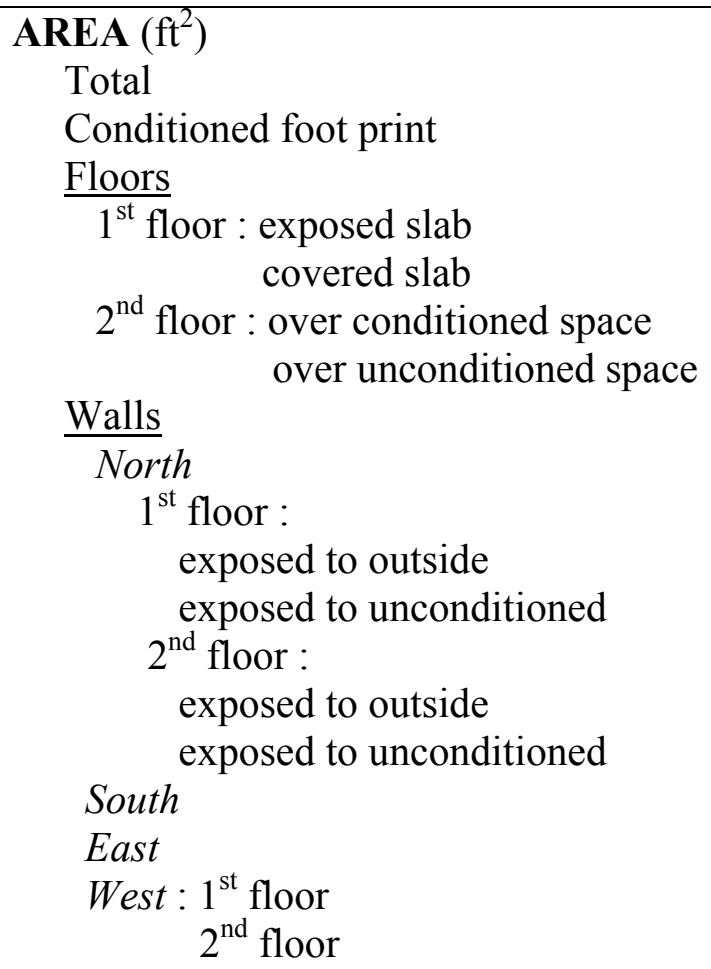 & $\begin{array}{c}180 \\
176 \\
132 \\
44 \\
532 \\
504 \\
200 \\
104\end{array}$ & $\begin{array}{l}\text { AREA }\left(\mathrm{ft}^{2}\right) \\
\text { Ceilings } \\
\text { Vaulted } \\
\text { Horizontal } \\
\frac{\text { Doors }}{\text { Garage }} \\
\text { Front } \\
\text { Glass } \\
\text { North } \\
\text { South } \\
\text { East } \\
\text { West } \\
\text { Thermal Mass } \\
\text { Covered } \\
\text { Exposed } \\
\text { SLOPE ANGLE } \\
\text { Roof Pitch }\end{array}$ & $\begin{array}{c}20 \\
20 \\
\mathbf{1 6 \%} \\
70.4 \\
70.4 \\
70.4 \\
70.4\end{array}$ \\
\hline
\end{tabular}

\begin{tabular}{|c|c|c|c|c|}
\hline \multirow[t]{2}{*}{ Orientation } & \multirow[t]{2}{*}{ Window } & Area $\left(\mathrm{ft}^{2}\right)$ & \multirow{2}{*}{$\begin{array}{c}\text { Left } \\
\text { Distance }\end{array}$} & \multirow[t]{2}{*}{ Head Height } \\
\hline & & $16 \%$ & & \\
\hline North & $\begin{array}{l}\text { A1 } \\
\text { A2 } \\
\text { A3 } \\
\text { B }\end{array}$ & 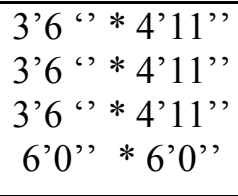 & $\begin{array}{c}\text { 1'0', } \\
\text { 8'0', } \\
\text { 14'0', } \\
\text { 5'0', }\end{array}$ & $\begin{array}{l}15^{\prime} 0^{\prime \prime} \\
15^{\prime} 0, \\
15^{\prime} 0, \\
70^{\prime},\end{array}$ \\
\hline South & $\begin{array}{l}\text { C } \\
\text { D1 } \\
\text { D2 } \\
\text { D3 } \\
\end{array}$ & 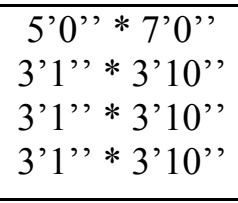 & 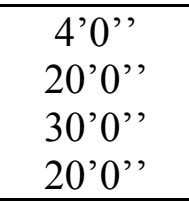 & $\begin{array}{c}7^{\prime} 0^{\prime \prime} \\
15^{\prime} 0^{\prime}, \\
15^{\prime} 0^{\prime \prime} \\
7^{\prime} 0^{\prime \prime}\end{array}$ \\
\hline East & $\begin{array}{l}\text { E1 } \\
\text { E2 } \\
\text { E3 } \\
\text { E4 }\end{array}$ & 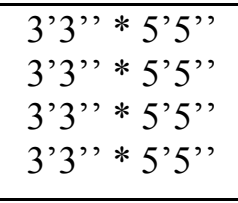 & $\begin{array}{l}4^{\prime} 0^{\prime \prime}, \\
27^{\prime} 0 \text { ', } \\
3^{\prime} 0^{\prime}, \\
14^{\prime} 0 \text { ', }\end{array}$ & $\begin{array}{l}15^{\prime} 0^{\prime}, \\
15^{\prime} 0 ', \\
7 ' 0 ’ \\
7 ' 0 ',\end{array}$ \\
\hline West & $\begin{array}{l}\mathrm{F} \\
\mathrm{G} 1 \\
\mathrm{G} 2\end{array}$ & $\begin{array}{l}3^{\prime} 2^{\prime}, * 4^{\prime} 0^{\prime \prime} \\
5^{\prime} 6^{\prime}, 5^{\prime} 3^{\prime \prime} \\
5^{\prime} 6^{\prime}, 5^{\prime} 3^{\prime}\end{array}$ & $\begin{array}{l}4^{\prime} 0^{\prime}, \\
4^{\prime} 00^{\prime}, \\
15^{\prime} 0^{\prime}\end{array}$ & $\begin{array}{l}15^{\prime} 0{ }^{\prime \prime} \\
7 ’ 00 ', \\
7 ’ 0 '\end{array}$ \\
\hline
\end{tabular}




\section{Appendix 7: DETAILS OF HOUSE DESCRIPTION USED AS INPUT TO REGCAP}

\section{Determination of the Envelope Leakage Coefficient: $\mathrm{C}$}

The typical relationship used between the flow $\mathrm{Q}$ and the pressure difference is: $\mathrm{Q}=\mathrm{C} \Delta \mathrm{P}^{\mathrm{n}}$ Where $\mathrm{Q}=$ Volume Flow Rate $\left(\mathrm{m}^{3} / \mathrm{s}\right)$

$\mathrm{C}=$ Flow coefficient $\left(\mathrm{m}^{3} /\left(\mathrm{sPa}^{\mathrm{n}}\right)\right)$

$\mathrm{n}=$ Flow exponent

The value of $\mathrm{n}$ varies from 1 for laminar flow to 0.5 for turbulent orifice flow. The sign of $\Delta \mathrm{P}$ issued in REGCAP to give the flow direction: if it is positive, it is an inflow if not it is an outflow.

Title 24 provides the default Specific Leakage Area that must be converted to a flow coefficient, $\mathrm{C}$, using the following relationships:

$$
\begin{array}{ll}
\mathrm{SLA}=\mathrm{ELA} 69.44 / \mathrm{FA}=3.8 \quad \text { with } & \begin{array}{l}
\mathrm{ELA}=\text { Effective Leakage Area }\left(\mathrm{m}^{2}\right) \\
\mathrm{FA}=\text { Floor Area }\left(\mathrm{ft}^{2}\right)
\end{array} \\
\mathrm{ELA}=\mathrm{SLA} \cdot \mathrm{FA} / 69.44 &
\end{array}
$$

We assume that this flow can be calculated as a flow through an orifice at e reference pressure of $4 \mathrm{~Pa}$ :

$$
\begin{aligned}
\mathrm{Q}=\mathrm{C} \Delta \mathrm{P}^{\mathrm{n}} & =\mathrm{ELA} \sqrt{\frac{2 \Delta P}{\rho}}=\operatorname{ELA} \Delta \mathrm{P}^{0.5} \sqrt{\frac{2}{\rho}} \text { with } \rho=1.2, \Delta \mathrm{P}=4 \mathrm{~Pa} \text { (standard values) } \\
\mathrm{C} & =\mathrm{ELA} \sqrt{\frac{2}{\rho}} \Delta \mathrm{P}^{0.5-\mathrm{n}}=0.066 \mathrm{~m}^{3} /\left(\mathrm{sPa}^{\mathrm{n}}\right) ; \text { with } \mathrm{n} \text { assumed to be equal to } 0.67
\end{aligned}
$$

\section{Determination of House UA}

The equation for the heat flow is:

Heat loss $=\mathrm{UA} \Delta \mathrm{T}$ with $\Delta \mathrm{T}=$ difference of temperature between the indoor temperature and the outdoor temperature

$$
\begin{aligned}
& \mathrm{A}=\text { Sum of the ceiling, walls, and floor Area } \\
& \mathrm{U}=\text { Thermal Conductivity }=1 / \mathrm{R} \text { (thermal resistance). } \\
& \mathrm{UA}=\frac{A_{\text {ceiling }}}{R_{\text {ceiling }}}+\frac{A_{\text {floor }}}{R_{\text {floor }}}+\frac{\sum_{n=1}^{4} A_{\text {wall }}}{R_{\text {wall }}}
\end{aligned}
$$




\section{Determination of the Internal gains $(W)$}

Internal gains account for lights, electrical devices, and human beings. From the ASHRAE Handbook 1997, we can estimate the occupancy loads. The sensible heat gain per sedentary occupant is assumed to be $67 \mathrm{~W}$. We assume that there are 2 occupants, so, the internal gain due to the occupants is $134 \mathrm{~W}$. Appliance loads are concentrated mainly in the kitchen and laundry areas. Based on contemporary living conditions in a single-family house, a sensible load of 470W should be divided between the kitchen and/or laundry and the adjoining rooms.

Internal gains $(\mathrm{E})$ are the sum of these loads: $\mathrm{E}=604 \mathrm{~W}$

\section{Determination of the Attic Leakage Coefficient, $C_{a t t i c}$}

This coefficient was based on field measurements in test houses, together with a scaling factor to account for the difference in house size between the field tests and the simulated house.

\section{Supply and return leakage fraction}

Three levels of duct leakage were used, based on field tests on many duct systems by LBNL and other researchers and contractors:

- Good ducts: 3\%

- Typical ducts: $11 \%$

- Poor ducts: $14 \%$

\section{Determination of the return and supply duct length and diameter}

The Return Surface Area (RSA) and the Supply Surface Area (SSA) scale with the Floor Area (FA) in the following way (from Walker (1998)):

$$
\begin{array}{rlll}
\mathrm{RSA} & =5 \% * \mathrm{FA} & & \\
\mathrm{SSA} & =27 \% * \mathrm{FA} & \text { if } & 1 \text { story house } \\
& =0.7 * 0.27 * \mathrm{FA} & \text { if } & 2 \text { story house }
\end{array}
$$

We used a typical value of the return and supply 10 inches diameter to determine the length of these ducts.

\section{Envelope leakage distribution}

$\mathrm{R}=\left(\mathrm{C}_{\text {ceiling }}+\mathrm{C}_{\text {floor }}\right) / \mathrm{C}_{\text {total }}=0.4$ Fraction of envelope leakage in ceiling and floor

$\mathrm{X}=\left(\mathrm{C}_{\text {ceiling }}-\mathrm{C}_{\text {floor }}\right) / \mathrm{C}_{\text {total }}=0.3$ Difference between ceiling and floor

These two values are estimated based on field measurements. If the house is located on a slab (like in our case), ceiling losses will be bigger than floor losses. But if the house is over a crawlspace, the term $\mathrm{X}$ will become smaller because of the cracks that increase floor losses. 


\section{Appendix 8: ACCA MANUAL J FURNACE SIZING SUMMARY}

ACCA manual $\mathrm{J}$ calculations were used to determine the capacity of the heating equipment needed in each climate. The range heating of loads ranged from $22 \mathrm{k}$ Btu/h for the hot climate zone (climate zone 7 ) and $44 \mathrm{k} \mathrm{Btu} / \mathrm{h}$ for the mountain climate zone (climate zone 16), and are summarized in the following table.

\begin{tabular}{|c|c|c|c|}
\hline \multicolumn{4}{|c|}{ Capacity of heating system given by ACCA R-J for different climate zones } \\
\hline Climate Zone & Capacity, kW ( kBtu/h ) & Climate Zone & Capacity, kW ( kBtu/h ) \\
\hline 1 & $9(31)$ & 9 & $9(31)$ \\
\hline 2 & $10(34)$ & 10 & $7(24)$ \\
\hline 3 & $7(24)$ & 11 & $9.5(33)$ \\
\hline 4 & $9(31)$ & 12 & $9(31)$ \\
\hline 5 & $9(31)$ & 13 & $9.5(33)$ \\
\hline 6 & $6.5(22)$ & 14 & $10(34)$ \\
\hline 7 & $6(21)$ & 15 & $9(31)$ \\
\hline 8 & $9(31)$ & 16 & $13(45)$ \\
\hline
\end{tabular}

